\title{
Family Ties and Child Obesity in Italy
}

This is the peer reviewed version of the following article:

Original:

Crudu, F., Neri, L., Tiezzi, S. (2021). Family Ties and Child Obesity in Italy. ECONOMICS AND HUMAN BIOLOGY, 40 [10.1016/j.ehb.2020.100951].

Availability:

This version is availablehttp://hdl.handle.net/11365/1121496

since 2020-12-02T12:58:09Z

\section{Published:}

DOI:10.1016/j.ehb.2020.100951

Terms of use:

Open Access

The terms and conditions for the reuse of this version of the manuscript are specified in the publishing policy. Works made available under a Creative Commons license can be used according to the terms and conditions of said license.

For all terms of use and more information see the publisher's website.

(Article begins on next page) 


\section{Journal Pre-proof}

Family Ties and Child Obesity in Italy $<!-<$ ForCover $>$ Federico Crudu, Laura Neri, Silvia Tiezzi, Family Ties and Child Obesity in Italy, $<![C D A T A[E c o n o m i c s$ and Human Biology]]>, doi:10.1016/j.ehb.2020.100951</ForCover>->

Federico Crudu, Laura Neri, Silvia Tiezzi

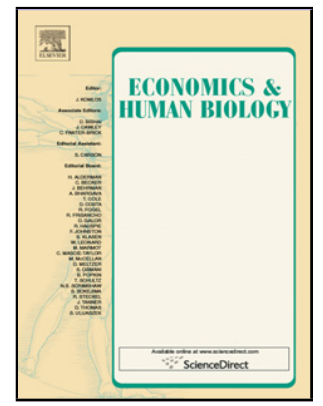

PII: $\quad$ S1570-677X(20)30221-5

DOI: $\quad$ https://doi.org/10.1016/j.ehb.2020.100951

Reference: $\quad$ EHB 100951

To appear in: $\quad$ Economics and Human Biology

Received Date: 21 January 2020

Revised Date: 25 October 2020

Accepted Date: $\quad 16$ November 2020

Please cite this article as: \{ doi: https://doi.org/

This is a PDF file of an article that has undergone enhancements after acceptance, such as the addition of a cover page and metadata, and formatting for readability, but it is not yet the definitive version of record. This version will undergo additional copyediting, typesetting and review before it is published in its final form, but we are providing this version to give early visibility of the article. Please note that, during the production process, errors may be discovered which could affect the content, and all legal disclaimers that apply to the journal pertain.

(C) 2020 Published by Elsevier. 


\title{
Family Ties and Child Obesity in Italy*
}

\author{
Federico Crudu ${ }^{\dagger}$ \\ University of Siena and CRENoS
}

\author{
Laura Neri ${ }^{\ddagger}$ \\ University of Siena
}

\author{
Silvia Tiezzi $§$
}

University of Siena

October 2020

\begin{abstract}
This paper examines the impact of overweight family members on weight outcomes of Italian children aged 6 to 14 years. We use an original dataset matching the 2012 cross sections of the Italian Multipurpose Household Survey and the Household Budget Survey. Since the identification of within-family peer effects is known to be challenging, we implement our analysis on a partially identified model using inferential procedures recently introduced in the literature and based on standard Bayesian computation methods. We find evidence of a strong, positive effect of both overweight peer children in the family and of overweight adults on children weight outcomes. The impact of overweight peer children in the household is larger than the impact of adults. In particular, the estimated confidence sets associated to the peer children variable is positive with upper bound around one or larger, while the confidence sets for the parameter associated to obese adults often include zero and have upper bound that rarely is larger than one.
\end{abstract}

Keywords: child obesity; confidence sets; partial identification; peer effects within the family.

*We thank three anonymous referees and the Associate Editor Tinna Ásgeirsdóttir, whose comments greatly improved the paper. Comments from Pamela Giustinelli, Giovanni Mellace, Nicole Hair, and participants at the 2018 Workshop on Institutions, Individual Behavior and Economic Outcomes, Alghero, Italy; the IAAE 2019 Conference, Nicosia, Cyprus; the Nordic Health Economic Study Group (NHESG) 2019, Reykjavik, Iceland; and the 2019 Annual Health Econometrics Workshop, Knoxville TN, USA are gratefully acknowledged.

${ }^{\dagger}$ Department of Economics and Statistics, University of Siena, Piazza San Francesco, 7/8 53100 Siena, federico.crudu@unisi.it.

${ }^{\ddagger}$ Department of Economics and Statistics, University of Siena, Piazza San Francesco, 7/8 53100 Siena, laura.neri@unisi.it.

${ }^{\S}$ Department of Economics and Statistics, University of Siena, Piazza San Francesco, 7/8 53100 Siena, silvia.tiezzi@unisi.it. 


\section{$1 \quad 1$ Introduction}

2 In the last decades children overweight and obesity prevalence have risen substantially in 3 most countries. According to a new global assessment of child malnutrition by UNICEF 4 (UNICEF, 2019) the most profound increase has been in the 5-19 age group, where the 5 global rate of overweight increased from $10.3 \%$ in 2000 to $18.4 \%$ in 2018.

Identifying the determinants of child obesity is a compelling issue since obesity is not only a direct threat for children's health and a cost to society, but also has documented consequences for adult life, such as effects on health (Llewellyn et al., 2016), on self-esteem, body image and confidence, and on wages (Schwartz et al., 2011).

It is recognised that child consumption decisions are affected by those of their peers (Dishion \& Tipsord, 2011) and that peer effects are more pronounced in children than in adolescents (Nie et al. 2015). While classroom or friends peer effects have been found to explain childhood and adolescents obesity (Asirvatham et al. 2014; Gwozdz et al., 2015 Nie et al., 2015), the role of within-the-family peers, e.g. interaction with other overweight and obese peer children in the family, as a determinant of child overweight and obesity has not yet been investigated 1

In fact, within-the-family social interaction could be an important determinant of child obesity, because children spend most of their time in the family environment. A likely driving mechanism is imitation. Research in experimental psychology (Zmyj, Ascherslebel et al., 2012, Zmyj, N. Daum et al., 2012; Zmyj \& Seehagen, 2013) postulates that prolonged individual experience with peers leads children to imitate peers more than adults. Children imitate familiar behaviour for social reasons, such as identification with the role model or to communicate likeness. Adults are the natural model on which children rely in unfamiliar situations while age is an important indicator of likeness. With prolonged contact with peers (i.e. children in the same age group), children are more likely to imitate behaviour

\footnotetext{
${ }^{1}$ An exception is the famous study by Christakis \& Fowler (2007) focusing on adults. One of their main findings was that, among pairs of adult siblings, if one sibling became obese, the chance that the other would become obese increased by $40 \%$ and that if one spouse became obese, the likelihood that the other spouse would also become obese increased by $37 \%$.
} 
1 from them than from adults, because they learn to trust their peers and to refer to them

2 for learning also in unfamiliar situations. In this case imitation serves a cognitive function:

3 prolonged contact with peers leads children to believe that peers are as competent as

4 adults, i.e. a reliable model. Since children plausibly spend extended periods of time with

5 family members, such prolonged contact is reflected in increased levels of peers imitation.

6 If imitation is the driving mechanism through which within-the-family social interaction

7 affects child obesity, then the impact of peer children in the family should be larger than

8 the impact of adults.

9 The purpose of this paper is to investigate whether the presence of other overweight/obese

10 family members, i.e. children in the same age group and adults, has a positive and signi-

11 ficant effect on the probability of a child being overweight/obese. To address this research

12 question we use a unique cross-section of Italian households containing detailed inform-

13 ation on families' structure, composition, habits, and weight outcomes. We estimate a

14 binary choice model where the dependent variable is a binary indicator for each child be-

15 ing overweight or obese or not. The main explanatory variables of interest are the share

16 of other overweight or obese children in the same age group in the family, and the share of

17 overweight or obese adults in the family.

To assess the impact of children in the same age group and family (our peer effect), we use a narrow peer-group definition that includes all children aged 6 to 14 years belonging to the same family whether siblings or not. While assessing the impact of adults does not pose particular challenges, within-the-family peer effects are particularly difficult to identify. Narrow definitions of the peer group, such as ours, have been found to be more endogenous than broad ones, because of shared common traits, habits and environments that may cause simultaneity effects (Black et al., 2017; Trogdon et al., 2008). A shared environment also complicates the problem of controlling for unobserved fixed effects, because the latent heterogeneity that may affect the weight outcome of each child is likely to affect the weight outcome of the other children in the same family and age group.

In order to provide some further intuition on the mechanics of our problem and on 
1 the potential causal interpretation of the model, let us consider a simple directed acyclic 2 graph (DAG) (see Figure 11) to represent the relationship among the main variables of 3 our model. Our main problem is to study the relationship of the peer effect variable 4 (Peer) on the obesity score (Obesity) of a given child in the family. We may reasonably 5 conjecture that Obesity would depend on Exogenous and Contextual variables as well 6 as other Unobserved characteristics. Identifying peer effects may be complicated for a 7 number of reasons. First, in the context of a group of siblings the assignment to a given 8 family is nonrandom and it would reasonably depend on the characteristics of the parents $:^{2}$ 9 Second, genetic and behavioral characteristics may be important to determine whether an 10 individual is obese or not. The former set of characteristics more than the latter may 11 be difficult to observe. However, there may exist some suitable proxy variables that may 12 work as mediators between the Unobserved variables and Peer, these may be physical 13 characteristics such as adults' weight and height (or BMI) and history of chronic diseases. 14 If this is the case, by controlling for the Exogenous effects and the Contextual effects in 15 Figure 1 we may be able to identify the causal relation between Peer and Obesity. The assumption that Unobserved does not affect Peer may be difficult to maintain in some 17 applications. In the analysis of peer effects in the classroom context, for example, one would 18 reasonably assume that such unobserved factors may be related to family characteristics 19 and in particular to teacher quality. In this case, i.e. if Unobserved affects Peer, identifying the causal effect of Peer on Obesity may be impossible.

\footnotetext{
${ }^{2}$ The implicit assumption here is that family members are consanguineous.
} 


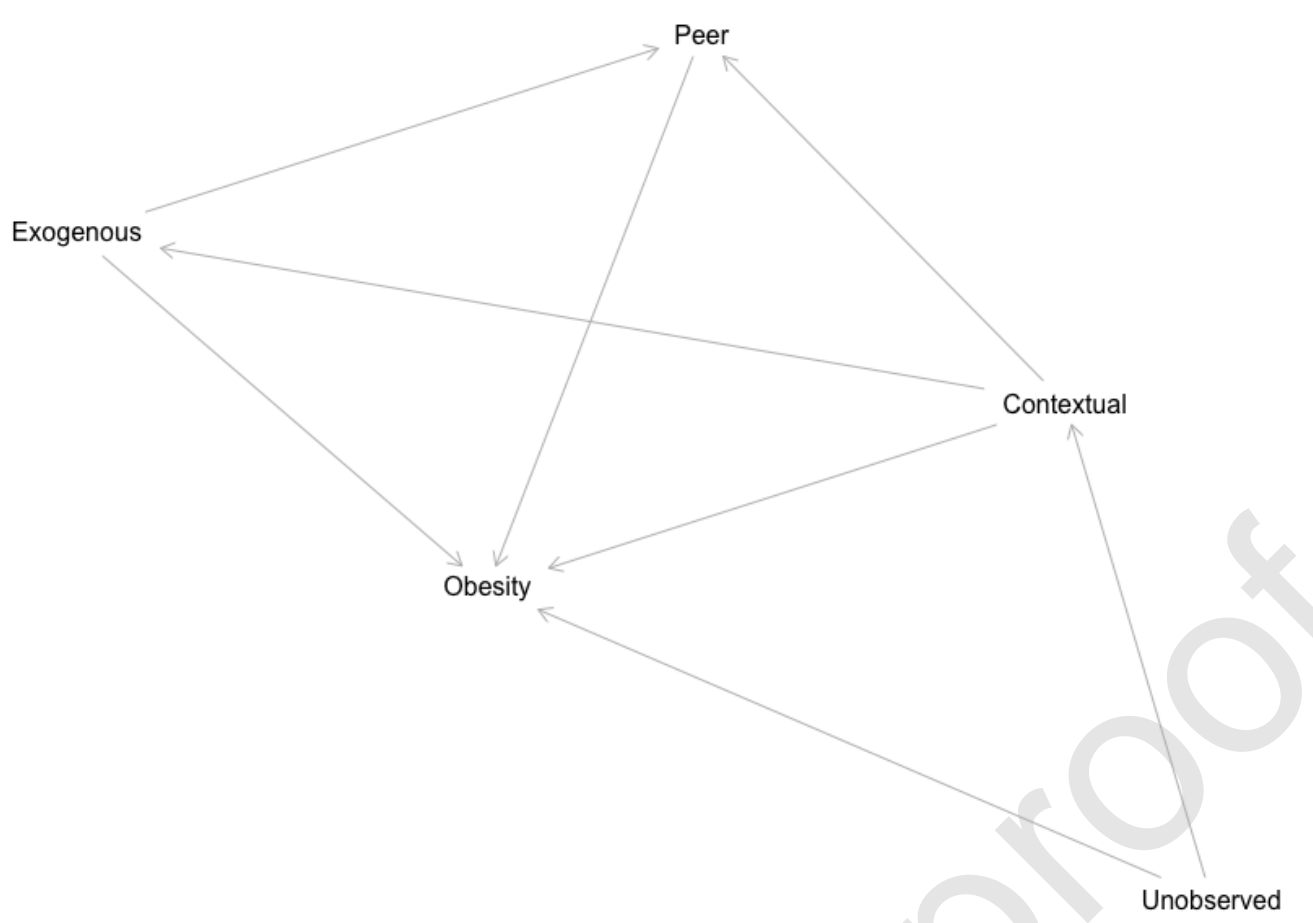

Figure 1: This DAG shows the causal relationship between Obesity and the peer effect variable Peer. In this model, controlling for Exogenous and Contextual allows one to identify the causal effect of Peer on Obesity.

1 Due to the narrow peer group and to the structure of the data, however, our identific-

2 ation problem remains hard to solve. We resort to a binary choice model and to partial

3 identification results for such models (see Section 4 for further details on the identification

4 problem and, e.g., Blume et al., 2011; Brock \& Durlauf, 2001, 2007).

$5 \quad$ Inferential procedures for partially identified models are often rather complicated. How-

6 ever, the method we use in this paper, introduced by Chen et al. (2018), is computationally

7 rather simple and boils down to calculating confidence sets for the parameters of interest

8 by means of standard Bayesian computation methods. Consistently with the hypothesised

9 driving mechanism, we find evidence of a strong, positive and statistically significant effect

10 of overweight and obese peer children and a smaller positive and generally statistically

11 significant effect of overweight and obese adults in the family on children's obesity.

12 Our contribution to the existing literature is threefold. First, to our knowledge this is

13 the only paper studying the causal role of within-family peer effects on obesity as a relevant 
1 health outcome. If peers in the family have important influences on child weight outcomes,

2 policies affecting one child in the family may have beneficial effects on the other children

3 as well as a social multiplier effect.

$4 \quad$ Second, as stressed by Blume et al. (2011), the literature on partial identification for 5 social interaction models has evolved separately from that on the estimation of partially

6 identified models via bounds initiated by Tamer (2003) and used in industrial organization.

7 This paper is an attempt to integrate these two bodies of literature in a very specific

8 context.

$9 \quad$ Finally, this is the only study on social interaction and child obesity in Italy. Obesity 10 rates are low in Italy compared to most OECD countries, but the picture is different for 11 children. According to the fifth wave of the Italian Surveillance System Okkio alla Sa12 lute, in 2016 the prevalence rates of overweight (including obese) and obese primary school 13 children were $30.6 \%$ and $9.3 \%$, respectively, with southern regions displaying higher rates 14 than northern regions (Lauria et al. 2019). The Surveillance System Okkio alla Salute 15 (http://www.epicentro.iss.it/okkioallasalute/) monitors overweight and obesity of 16 Italian children in primary schools (6-11 years of age). The System, promoted and financed 17 by the Italian Ministry of Health, was started in 2007 and participates in the World Health ${ }_{18}$ Organization (WHO) European Childhood Obesity Surveillance Initiative (COSI). In ad19 dition, family ties are culturally strong in Italy which makes social interaction within the 20 family a particularly interesting issue to explore.

${ }_{21}$ The remainder of the paper unfolds as follows. Section 2 summarizes the literature. 22 Section 3 describes the data. Section 4 discusses our identification strategy. Section 5 ${ }_{23}$ presents the estimation methods and main results. Section 6 concludes. Finally, the Ap24 pendix contains a description of statistical matching, results for the full sets of parameters 25 and the results of the robustness checks. 


\section{Child Obesity and Peer Effects}

2 The main recognized cause of the rise in child obesity is an imbalance between calorie intake

3 and calorie expenditure. There is a vast literature on the factors driving this imbalance.

4 One strand has addressed the relationship between maternal employment and child obesity

5 in many developed countries. Maternal employment is usually associated with higher child

6 weight outcomes, because employed mothers may have less time to pay attention to their

7 children's diet (Cawley \& Liu, 2012; Champion et al. 2012; Fertig et al., 2009; Gaina et al.

8 2009, García et al. 2006, Greve, 2011; Gwozdz et al., 2013; Liu et al. 2009, Morrill, 2011

9 to cite only a few). Overall, these studies find empirical evidence of a positive relationship

10 between maternal employment and childhood obesity. However, there is no evidence of such

11 positive relationship in Italy. In Italy there is a female labor force participation divide and

12 a child obesity divide. The South has a very low female labor force participation compared

13 to the North, but child obesity prevalence is much higher in the South compared to the

14 North (Brilli et al. 2016).

A related factor is the increasing use of non-parental child care (informal care by a relative, care by a baby-sitter and centre-based care) which may increase the likelihood of obesity (Herbst \& Tekin, 2011; Hubbard 2008). The growing use of non-parental care

may play a crucial role in shaping children's habits through the quality of the food offered and the level of physical activity. Herbst \& Tekin (2011) find that centre-based care is associated with large and stable increases in BMI throughout its distribution, while the impact of other non-parental arrangements appears to be concentrated at the tails of the distribution.

A strand of literature, initiated by Christakis \& Fowler (2007), has emerged in health economics that addresses the influence of social interaction, particularly of peers, on health status. In their seminal paper Christakis \& Fowler (2007) conducted a study to determine whether adult obesity might spread from person to person. Their starting point was that people embedded in social networks are influenced by the behaviours of those around 
1 them such that weight gain in one person might influence weight gain in others. That

2 study focused on social interaction among adults. A follow up study by the same authors

3 (Fowler \& Christakis, 2008) produced evidence of person-to-person spread of obesity also

4 in adolescents.

5 Powell et al. (2015) has identified social contagion, i.e. the phenomenon whereby the 6 network in which people are embedded influences their weight over time, as one of the 7 social processes explaining the rise of adult overweight and obesity. The general finding

8 is that weight-related behaviours of adolescents are affected by peer contacts (Fowler \& 9 Christakis, 2008; Halliday \& Kwak, 2009, Mora \& Gil, 2013; Renna et al., 2008, Trogdon 10 et al. 2008). These studies take adolescents as the relevant age group and the classroom 11 or friends as the relevant network. Much less is known about children as the relevant age 12 group and the family as the relevant network..$^{3}$

13 To the best of our knowledge only four studies, besides ours, analyse peer effects among 14 children as the relevant population, and child obesity as the relevant outcome. Asirvatham 15 et al. (2014) study peer effects in elementary schools using measured obesity prevalence 16 for children cohorts within schools and using a panel dataset at grade level from Arkansas 17 public schools. They found that changes in the obesity prevalence at the highest level 18 are associated with changes in obesity prevalence at lower grades and the magnitude of 19 the effect is greater in kindergarten to fourth-grade schools than in kindergarten to sixth20 grade schools. Nie et al. (2015) analyse peer effects on obesity in a sample of 3 to 18 21 years old children and adolescents in China. Peer effects are found to be stronger in rural 22 areas, among females and among individuals in the upper end of the BMI distribution. 23 Gwozdz et al. (2015) analyse peer effects on childhood obesity using a panel of children 24 aged 2 to 9 from eight European countries. They show that, compared to the other 25 European countries in the sample, peer effects are larger in Spain, Italy and Cyprus. These 26 studies adopt a fairly broad definition of peer effects, either peers at the same grade level

\footnotetext{
$\sqrt[3]{\text { Nie et al. }}(2015)$ report that most of the empirical literature on peer effects and obesity refers to adolescents or adults and uses US data.
} 
1 within a school or children in a similar age group within a specific community. Finally,

2 Yajuan et al. (2016) estimate peer effects on third grade students' BMI from a childhood

3 obesity intervention program targeted at elementary schools students in Texas. Peer effects

4 were found for students aged 8-11, with gender differences in the psychological and social

5 behavioral motivations.

$6 \quad$ None of the above studies focuses on the family as the relevant peer group.

$7 \quad$ The literature on the causal role of siblings on children's outcomes is recent and growing.

8 This literature has focused on the effects of sibling health status on educational outcomes

9 (Black et al., 2017; Fletcher et al., 2012), on the effect of early health shocks on child

10 human capital formation (Yi et al. 2015), on the effects of teen motherhood on their

11 siblings' short and medium term human capital development (Heissel, 2017, 2019), on the

12 effect of siblings on educational choices and early career earnings (Dustan, 2018, Joensen \&

13 Nielsen, 2018; Nicoletti \& Rabe, 2019; Qureshi, 2018), and on the effects of health shocks

14 to individuals on their family members consumption of preventive care (Fadlon \& Nielsen

15 2019).

${ }_{16}$ Our study contributes to the latter strand of literature considering children as the 17 relevant population and obesity as the relevant health outcome. We conjecture that the 18 mechanism through which the peer effect plausibly operates is via imitation of good and 19 bad behaviours such as eating habits.

\section{3 Data and Matching}

${ }_{21}$ The choice of the family as the relevant network to analyse peer effects complicates the 22 problem of controlling for unobserved fixed effects. Thus, the amount of available inform${ }_{23}$ ation is a crucial issue in our case. Studies of peer effects and childhood obesity usually 24 include information on economic characteristics of the household, such as income, in ad25 dition to personal and socio-demographic information, because low-income individuals are more likely to be obese than those with high-income (Trogdon et al. 2008). Moreover, the 
1 relationship between income and weight is reported to vary by gender, race/ethnicity and 2 age. ${ }^{4}$ Lacking a single Italian cross section containing individual weight outcomes, detailed

3 family characteristics and socio-economic variables, we used statistical matching (SM) to 4 match two datasets. The first is the 2012 cross section of the Multipurpose Survey on

5 Households: Aspects of Daily Life (MSH) containing detailed information on family char6 acteristics and the weight outcome of each member. The second is the 2012 cross section of 7 The Household Budget Survey (HBS) covering details of current and durable expenditures.

8 Both surveys are conducted by the Italian National Statistical Institute (ISTAT).

9 The MSH for the year 2012 is a large nationally representative sample survey covering $10 \quad 19,330$ households and 46,463 family members, including children aged 6 to 14 years.5

11 The questionnaire, administered by paper and pencil, contains three blocks of questions: a 12 general questionnaire on individual characteristics of the first six members of the household; 13 a family questionnaire collecting information about household habits and lifestyles; a diary 14 of health and nutritional information for each member of the household. For children and 15 adolescents aged 6-17 a binary indicator for whether the child is overweight or obese is also 16 included. Identification of a child as overweight or obese is based on BMI threshold values 17 for children aged 6 to 17 developed by Cole et al. (2000) and adopted by the International 18 Obesity Task Force (IOTF). The MSH does not contain information on expenditures that 19 could be important covariates in our empirical model. We obtain this information from 
1 characteristics (such as regional location, household size, gender, age, education and em2 ployment condition of each household member). For both surveys, annual samples are 3 drawn independently according to a two-stage design ${ }^{6}$ In addition to having a large set 4 of variables in common, the two surveys share many characteristics such as the target 5 population, sampling method, geographic frame and data collection procedure. These 6 common characteristics allow us to use SM as an ideal method for combining information 7 on households' quality of life and child weight outcomes with information on households' 8 consumption expenditures.7

9 The sample under analysis includes 3,906 observations. The unit of analysis is defined 10 as child aged between 6 and 14 years: the barplot in Figure 2 panel (a) displays how 11 children are distributed across households. The 3,906 children involved in the analysis are 12 distributed across 2,954 households. As shown in Figure 2 panel (a), 2,095 children have 13 no siblings in the target age group: 6 to 14 years; 770 households have two children in 14 the same age group, for a total number of children equal to 1,540; 85 households have 15 three children in the same age group, thus the total number of children is 255; finally, 4 16 households have four children in the target age group, for a total amount of children equal 17 to 16.

For each individual, a rich set of covariates is available. Table 1 shows summary statchildren out of 3,906 , thus overweight/obese children account for $29 \%$ of children aged 6-14

\footnotetext{
${ }^{6}$ Details on the sampling procedure used to collect data in both surveys can be found in: ISTAT (2012) Indagine Multiscopo sulle Famiglie, aspetti della Vita quotidiana, Anno 2012, for the MSH survey; and in ISTAT (2012) File Standard-Indagine sui Consumi delle Famiglie-Manuale d'uso, anno 2012, for the HBS survey. Downloadable at http://www.istat.it/it/archivio/4021

${ }^{7} \mathrm{SM}$ of the two data sets is detailed in Appendix $\mathrm{A}$
} 
Table 1: Summary statistics. ${ }^{\dagger}$

\begin{tabular}{l}
\hline \hline \\
\hline Child obesity \\
Age \\
Gender (male)
\end{tabular}

Share of other overweight/obese children Share of overweight/obese adults Household size

Children born of previous marriage Monthly expenditure (Euro)

Employed RP

Student or housewife RP

Retired or other emp. status RP

Mother's education (Master)

Mother's education (Bachelor)

Mother's education (High School)

Mother's education (Junior High)

Mother's education (Primary School)

Central or northern region

Siblings (regularly) practising sport Siblings lunch at home

Siblings walking to school

Siblings TV watching every day

Parents soda drinks

Parents smoking

Children average fruit portions

Adults average fruit portions

Mean adult weight $(\mathrm{kg})$

Mean adult height $(\mathrm{cm})$

Chronic disease

Diabetes

CPI $(2010=100)$

$\%$ obese adults by region

\begin{tabular}{ccccc} 
Mean & S.d. & Min. & Max. & Obs. \\
\hline \multicolumn{5}{c}{ A. Individual characteristics } \\
\hline 0.292 & 0.455 & 0 & 1 & 3,906 \\
9.987 & 2.595 & 6 & 14 & 3,906 \\
0.495 & 0.500 & 0 & 1 & 3,906
\end{tabular}

\begin{tabular}{ccccc}
\hline \multicolumn{5}{c}{ B. Household characteristics } \\
\hline 0.072 & 0.174 & 0 & 0.667 & 3,906 \\
0.420 & 0.351 & 0 & 1 & 3,906 \\
4.120 & 1.018 & 2 & 11 & 3,906 \\
0.007 & 0.086 & 0 & 1 & 3,906 \\
2,131 & 1,346 & 237 & 16,998 & 3,906 \\
0.813 & 0.390 & 0 & 1 & 3,906 \\
0.053 & 0.225 & 0 & 1 & 3,906 \\
0.023 & 0.150 & 0 & 1 & 3,906 \\
0.126 & 0.331 & 0 & 1 & 3,906 \\
0.029 & 0.169 & 0 & 1 & 3,906 \\
0.348 & 0.476 & 0 & 1 & 3,906 \\
0.412 & 0.492 & 0 & 1 & 3,906 \\
0.068 & 0.252 & 0 & 1 & 3,906 \\
0.578 & 0.494 & 0 & 1 & 3,906 \\
& & & & \\
\hline
\end{tabular}

C. Behavioral characteristics

\begin{tabular}{ccccc}
\hline 0.176 & 0.244 & 0 & 0.75 & 3,906 \\
0.186 & 0.246 & 0 & 0.75 & 3,906 \\
0.089 & 0.193 & 0 & 0.75 & 3,906 \\
0.810 & 0.317 & 0 & 1 & 3,906 \\
0.155 & 0.362 & 0 & 1 & 3,906 \\
0.372 & 0.483 & 0 & 1 & 3,906 \\
1.125 & 0.754 & 0 & 5.5 & 3,906 \\
1.147 & 0.778 & 0 & 5.5 & 3,906
\end{tabular}

D. Proxies for genetic characteristics

\begin{tabular}{ccccc}
\hline 70.676 & 9.159 & 35.5 & 117.5 & 3,906 \\
168.959 & 5.694 & 110 & 193 & 3,906 \\
0.251 & 0.439 & 0 & 1 & 3,906 \\
0.034 & 0.181 & 0 & 1 & 3,906
\end{tabular}

E. Other characteristics

$\begin{array}{lllll}106.022 & 0.614 & 104.6 & 108.1 & 3,906\end{array}$

$\begin{array}{lllll}24.954 & 5.476 & 17.7 & 36.1 & 3,906\end{array}$

${ }^{\dagger}$ This table includes summary statistics on individual characteristics of children (panel A), household characteristics (panel B), in some cases related to the household's reference person (RP), behavioural variables (panel C), proxies for genetic characteristics (panel D), regional variables (panel E). 
1 years. The children's mean age is 10 and the percentage of male children is $49.5 \%$.

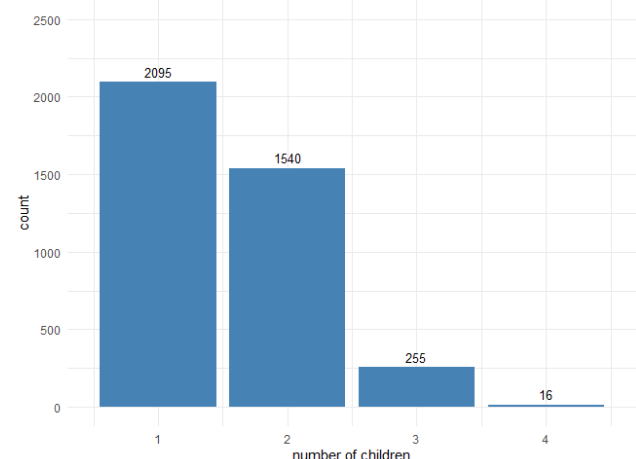

(a) Distribution of children across families $(6 \leq$ age $\leq 14)$.

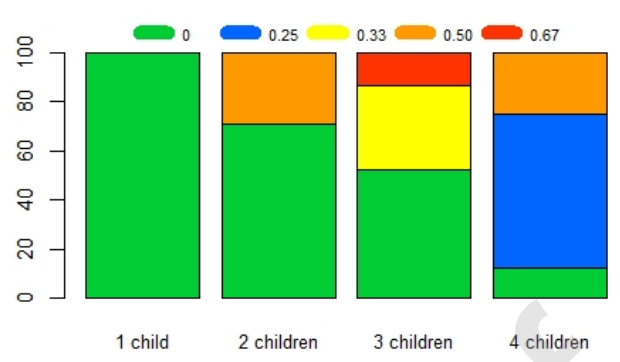

(b) Conditional distribution of obese/overweight children across families $(6 \leq$ age $\leq 14)$.

Figure 2: Children's distribution and share of obese children

2 The peer effect variable is defined as the share of other (overweight and obese) children

3 in the family (excluding the child considered). This variable, $m_{g_{-i}}$, is computed as the ratio

4 between the number of obese children in family $g$ excluding the reference child $i, n_{g_{-i}}^{O}$, and

5 the total number of children in the family, $n_{g}$. Hence,

$$
m_{g_{-i}}=\frac{n_{g_{-i}}^{O}}{n_{g}}
$$

$6 \quad$ where, in our data set, $1 \leq n_{g} \leq 4,0 \leq n_{g_{-i}}^{O} \leq 3$ and $0 \leq m_{g_{-i}} \leq \frac{2}{3}$. The minimum 7 value of the variable corresponds to two different cases. The first case occurs when child $i$ 8 has no siblings and the second occurs when child $i$ has no obese siblings. The maximum 9 value occurs when there are two out of three obese children in the family.

Figure 2 (panel b) shows the conditional distribution of the share of other obese/overweight

11 children in the family given the number of children in the target age group within the fam-

12 ily. Of course, if the reference child has no siblings, the share is zero. As to the children

13 having siblings in the age group 6-14, we can observe the following picture: the number

14 of children in families with two children in the target age group is 1,540, $71 \%$ of them

15 has a sibling with normal weight $($ share $=0$ ) and $21 \%$ has an obese/overweight sibling 
$1 \quad($ share $=1 / 2=0.5)$; the number of children in families with three children in the target 2 age group is $255,52 \%$ the of them has siblings with normal weight (share $=0$ ), $33 \%$ of 3 them has one obese/overweight sibling ( share $=1 / 3=0.33$ ), and the remaining $13 \%$ has 4 two obese/overweight siblings $($ share $=2 / 3=0.67)$. Finally, the number of children in 5 families with four children in the target age group is $16,12.5 \%$ of them has normal weight 6 siblings $($ share $=0), 62.5 \%$ has 1 obese/overweight sibling $($ share $=1 / 4=0.25)$ and $25 \%$ 7 of them has two obese/overweight siblings $($ share $=2 / 4=0.5)$.

$8 \quad$ Further characteristics shown in Table 1 include the share of overweight and obese adult 9 family members (42\%), household size (4 on average) and a dummy for children born from 10 a previous marriage, the employment status of the RP (three dummies for whether the 11 household RP is employed, a student or housewife, retired or in other employment positions 12 (e.g. military, unable to work, detained)), dummies for the level of education of the mother 13 (five dummies for whether the mother holds a Master's degree, a Bachelor's degree, has 14 attended High School, Junior High, or only Primary School) and a dummy for whether the 15 household lives in a central or northern Italian region. In addition, we include monthly 16 current expenditure, whose average value is 2,131 Euros. This variable is important as 17 it captures contextual effects and we conjecture that its support (237 - 16,998 Euros) is 18 sufficiently large to ensure that a nonlinear relationship with the share of obese children 19 in the family (the endogenous effect) exists. We also include a set of variables capturing behaviors of siblings in a wider age group (6 to 18 years) compared to the target age group, ${ }_{21}$ because older siblings could influence the behaviours of younger ones. Such variables include the share of siblings (excluding the child under consideration) aged between 6 and 18 watching TV every day, having lunch at home, practicing physical activities on a regular basis and walking to school, dummies for whether the parents consume soda drinks or smoke. We also include the child's daily average fruit portions and the adults daily average fruit portions. As proxies for the genetic variables we use the mean height and weight of the adult members of the family and two dummy variables for whether the RP or her spouse suffer from a chronic disease or diabetes. Finally, we use two additional 
1 variables at the regional level: the 2012 consumer price index (CPI) $(2010=100)$ and the 2 percentage of obese adults by region in 2012 .

\section{${ }_{3} 4$ Identification}

4 Our aim is to assess whether the presence of other overweight/obese family members,

5 i.e. children in the same age group and adults, has a positive and significant effect on

6 the probability of a child being overweight/obese. If imitation behaviour is the driving

7 mechanism we also expect that the impact of overweight/obese peer children in the family

8 is larger than the impact of overweight/obese adults. We use a narrow peer-group definition

9 that includes all children aged 6 to 14 years belonging to the same family (whether siblings

10 or not). Narrow definitions of peer groups have been found to be more endogenous than

11 broad ones. In particular Trogdon et al. (2008) report that broader measures of social

12 networks (e.g. grade-level peer groups) are more exogenous than narrow ones (e.g. children

13 in the same family) as they are likely to be determined by different causal mechanisms.

${ }_{14}$ While grade-level peer effects may be driven by BMI related social norms and body image

15 concerns, family-level peer effects may also operate through additional channels such as

16 the influence of diets, habits and physical activities. Christakis \& Fowler (2007) showed

17 that the influence of the weight of friends, family members and neighbours decreases with

18 increasing degrees of separation from the person under investigation. Despite the large

19 empirical literature on social interaction in a variety of contexts, identifying such effects

20 remains a formidable challenge.

${ }_{21}$ Let us consider the notation and the definitions in Brock \& Durlauf (2007). We assume

22 that individual binary weight outcomes are determined by five sets of factors:

23 (i) observable individual-specific characteristics known also as the exogenous effects, $24 \quad$ measured by an $r$-vector $X_{i}$;

25 (ii) unobservable individual characteristics summarized by a scalar $\varepsilon_{i}$; 
$1 \quad$ (iii) observable group characteristics, measured by an $s$-vector $Y_{g}$; these are known as con-

Thus, our model of social interaction can be described as

$$
\omega_{i}=k+c^{\prime} X_{i}+d^{\prime} Y_{g}+J m_{g_{-i}}+\varepsilon_{i}+\alpha_{g}
$$


1 large to establish a nonlinear relationship with $m_{g_{-i}}$. In addition to that, they derive 2 identification results also for the case of non random assignment provided that $\alpha_{g}=0$.

3 With respect to our context, the assumption of random assignment is very difficult to 4 justify. Since individuals within a group are consanguineous with high probability, their 5 assignment to a given group $g$ depends on common genetic traits. Unfortunately, our 6 data set does not contain any explicit information on the genetic factors that determine 7 obesity in the group. However, we may proxy it with mean adult height and weight in 8 the household and by adding two dummy variables for whether the household head or 9 her spouse suffers from a chronic disease or diabetes. We can conjecture that our proxies 10 capture sufficient information from the fixed effect to guarantee identification. However, 11 we cannot be sure that all relevant assumptions are met.

When point identification is not possible, Brock \& Durlauf (2007) describe a number 13 of situations where at least partial identification can be achieved. In particular, they 14 prove that under non random assignment, provided that $\alpha_{g}=0$ and the support on $Y_{g}$ is 15 sufficiently large to rule out the reflection problem, $J>0$ and $J$ is large enough to produce multiple equilibria. This means that group $g$ may coordinate on an equilibrium expected 17 average choice level other than the largest of the possible equilibria associated with it 18 while another group $g^{\prime}$ may coordinate on an equilibrium other than the lowest possible expected average choice level among those it could have attained. One of the situations where this may happen is the case of assortative matching, where higher group quality is related to higher individual quality. In our context, this may refer to the case where individuals within a specific group share common genetic traits or the same eating habits. It is, though, important to stress that the multiple equilibrium results in Brock \& Durlauf (2007) hold for large groups. In particular, Krauth (2006) suggests that multiplicity of equilibria for small groups may happen for lower threshold values of $J$.

We adopt Brock \& Durlauf (2007) approach to (partial) identification. In the empirical exercise we need to accommodate the large support assumption on $Y_{g}$. More specifically, we consider two cases. In the first case the variable with large support is the log of 
1 expenditures. The second specification includes also average adult weight and average 2 adult height. It is interesting to notice, though, that there seem to be no clear theoretical 3 guidelines on how many variables with large support would be necessary to avoid the 4 reflection effect (see e.g. Blume et al., 2011, p. 907).

5 Dealing with unobservable heterogeneity in the context of social interaction models is 6 generally a very challenging task since, as suggested in Blume et al. $(2011), \varepsilon_{i}$ and $\alpha_{g}$ are 7 undertheorized $9^{9}$ Nonetheless, there are still a number of approaches that can be exploited 8 when sufficient information is available. The most problematic issue in our setting is 9 how to deal with the group fixed effects $\alpha_{g}$. The simplest solution here is just to define ${ }_{10} \alpha_{g}=d^{\prime} Y_{g}+J m_{g_{-i}}\left(\right.$ Blume \& Durlauf 2006). This is, we approximate $\alpha_{g}$ with observables 11 and change the number of variables in $Y_{g}$ to assess the stability of the estimates. Our 12 model will include a large number of group characteristics that may reasonably determine 13 obesity and that are either related to genetic factors or to behavioural factors.10

Direct estimation of $\alpha_{g}$ via group dummies would be impossible in our context due to the large number of families $(2,954)$ compared to the number of individuals $(3,906)$. We could however identify a restricted number of groups by clustering families with common characteristics. The resulting number of groups would be considerably smaller than the total number of families. Allocating the families to specific groups may be done via an appropriate clustering algorithm. We give more details on this approach and on the corresponding results in Appendix B (Table B19 and Table B20).

Brock \& Durlauf (2007) propose a rather clever way to deal with $\alpha_{g}$. They suggest specifying $\alpha_{g}$ as a linear function of $Y_{g}$ and constructing an auxiliary variable $W_{i}=$ $F_{\varepsilon}^{-1}\left(P\left(\omega_{i}=1 \mid X_{i}, Y_{g}, \alpha_{g}\right)\right)$ where $F_{\varepsilon}$ is the distribution of $\varepsilon_{i}$. This would correspond to $W_{i}=k+c^{\prime} X_{i}+d^{\prime} Y_{g}+J m_{g_{-i}}+\alpha_{g}$. The construction of the sample analog for $W_{i}$ would rely on the existence of suitable information. ${ }^{17}$ In our case, once again, the limited availabil-

\footnotetext{
${ }^{9}$ Instrumental variables may be a viable option to deal with fixed effects. However, social interaction models do not generally suggest a theoretical justification to exclude variables from the model itself. This feature is known as openendedness (Blume et al., 2011).

${ }^{10} \mathrm{~A}$ recent strand of literature stresses that any similarity in weight due to shared household environments is undetectable and ignorable (Cawley \& Meyerhoefer, 2012; Kinge, 2016; Wardle et al., 2008)

${ }^{11}$ For the problem of social interactions in the classroom example, Brock \& Durlaut (2007) suggest using
} 
1 ity of data does not allow us to consider this alternative. A further interesting possibility is 2 due to Graham (2008), where $\alpha_{g}$ is interpreted as a random effect. Hence, $\operatorname{Cov}\left[\alpha_{g}, \varepsilon_{i}\right]=0$, 3 for $i \in g$. This approach is justified, at least in Graham's classroom problem, by the 4 random assignment of teachers to classrooms.

\section{${ }_{5} 5$ Estimation and Inference}

6 It is interesting to notice that the results in Brock \& Durlauf (2007) differ from the classical 7 approaches to partial identification. The latter case involves the identification of bounds 8 and their subsequent estimation by means of appropriate statistical procedures. Instead,

9 Brock \& Durlauf's (2007) theory-dependent approach studies how introducing unobserved 10 heterogeneity would affect the properties of the model. Furthermore, they do not establish 11 probability bounds (Blume et al. 2011).12 Hence, we assume that, given a certain para12 meter space $\Theta$, there exists a subset of $\Theta$, say $\Theta_{I}$, such that $F_{0}=F_{\theta}$ for $\theta \in \Theta_{I}$ where ${ }_{13} \quad F_{0}$ is the true distribution of the data and $F_{\theta}$ is our parametric model. We refer to $\Theta_{I}$ as 14 the identified set for which an appropriate estimator has to be found. In what follows, we 15 focus our attention on confidence sets for individual parameters. In this regard, we find 16 the following decomposition useful: $\theta=\left(\mu^{\prime}, \eta^{\prime}\right)^{\prime}$, where $\mu$ is the parameter vector we are 17 interested in and $\eta$ can be seen as a nuisance parameter. We denote the identified set for 18 the subvector $\mu$ as $M_{I}$.

19 We tackle the estimation problem by using a method introduced in Chen et al. (2018). 20 The confidence sets produced using this approach are simple to calculate, work well in finite 21 samples and asymptotically achieve frequentist coverage. The estimated confidence sets 22 can be compared to the confidence intervals produced by standard estimation methods 23 for binary choice models under the assumption of point identification. Intuitively, one 24 may argue that (lack of point) identification may not be an issue if confidence sets and 25 confidence intervals are similar.

test scores to recover a sample analogue for $W_{i}$.

${ }^{12}$ See, e.g., Manski (2003) and Molinari (in press) for a comprehensive treatment of partial identification. 
1 In this section we describe how we build valid confidence sets using Procedure 1 and

2 Procedure 3 in Chen et al. (2018). They are both simple to compute but the former tends

3 to produce conservative confidence sets while the latter can only be applied to scalar sub-

4 vectors of the parameter vector of interest. The associated numerical results are collected

5 in Table 2 to Table 9. Appendix B contains the robustness check results.

\section{$6 \quad 5.1$ Confidence Sets}

7 The methods proposed in Chen et al. (2018) exploit some classical ideas of Bayesian compu8 tation. The estimation of the confidence sets is in fact based on sampling from the posterior 9 distribution of the parameters. Here we provide a brief description of the three procedures 10 introduced in their paper. Considering the discussion in Section 4 on the treatment of the 11 fixed effect $\alpha_{g}$, the model that we estimate is

$$
\omega_{i}=Z_{i}^{\prime} \theta+u_{i}
$$

12 where $Z_{i}=\left(1, X_{i}^{\prime}, Y_{g}^{\prime}, m_{g_{-i}}\right)$ and $\theta=\left(k, c^{\prime}, d^{\prime}, J\right)^{\prime}$ is a $p$-dimensional vector where $p=$ ${ }_{13} 2+r+s{ }^{13}$ Let us consider a parametric loglikelihood function that depends on a parameter 14 vector $\theta$ that takes values in a set $\Theta$ and the data $Z_{i}$

$$
L_{N}(\theta)=\frac{1}{N} \sum_{i=1}^{N} \log f\left(\theta, Z_{i}\right)
$$

15 Let us denote the identified set as $\Theta_{I}=\left\{\theta \in \Theta: F_{0}=F_{\theta}\right\}$, where $F_{\theta}$ is our parametric 16 model and $F_{0}$ is the true distribution of the data. The posterior distribution, say $\Pi_{N}$, of $\theta$ 17 given the data $Z$ is

\footnotetext{
${ }^{13}$ For ease of notation we drop the group index $g$.
} 


$$
d \Pi_{N}(\theta, Z)=\frac{\exp \left(N L_{N}(\theta)\right) d \Pi(\theta)}{\int_{\Theta} \exp \left(N L_{N}(\theta)\right) d \Pi(\theta)}
$$

$1 \quad$ where $\Pi(\theta)$ is a prior distribution. The $100 \alpha \%$ confidence set, say $\widehat{\Theta}_{\alpha}$ for $\Theta_{I}$ is computed 2 in a three step procedure:

\section{Procedure 1 (whole parameter vector)}

${ }_{4}$ (a) draw $B$ samples $\left\{\theta^{(1)}, \ldots, \theta^{(B)}\right\}$ from the posterior distribution $\Pi_{N}$ via a Monte Carlo $5 \quad$ Markov chain (MCMC) sampler: ${ }^{14}$

$6 \quad$ (b) calculate the $(1-\alpha)$ quantile of $\left\{L_{N}\left(\theta^{(1)}\right), \ldots, L_{N}\left(\theta^{(B)}\right)\right\}$, say $\zeta_{N, \alpha}$;

7 (c) define $\widehat{\Theta}_{\alpha}$ as $\widehat{\Theta}_{\alpha}=\left\{\theta \in \Theta: L_{N}(\theta) \geq \zeta_{N, \alpha}\right\}$.

8 It is possible to adapt procedure 1 to construct confidence sets for the subset vector $9 \mu$. The so-called projection confidence set for $M_{I}$ is defined as $\widehat{M}_{\alpha}^{p r o j}=\left\{\mu:\left(\mu^{\prime}, \eta^{\prime}\right)^{\prime} \in\right.$ ${ }_{10} \widehat{\Theta}_{\alpha}$, for some $\left.\eta\right\}$. The projection confidence set is known to be conservative in particular 11 when the dimension of the subvector $\mu$ is smaller in comparison with the dimension of $\theta$. 12 Let us now define the set $H_{\mu}=\left\{\eta:\left(\mu^{\prime}, \eta^{\prime}\right)^{\prime} \in \Theta\right\}$ and the profile likelihood for $M_{I}$

$$
P L_{N}\left(M_{I}\right)=\inf _{\mu \in M_{I}} \sup _{\eta \in H_{\mu}} L_{N}(\mu, \eta)
$$

${ }_{13}$ Let $\Delta\left(\theta^{b}\right), b=1, \ldots, B$ be an equivalence set, i.e. a set of $\theta \in \Theta$ that produce the same 14 likelihood values and let $M\left(\theta^{b}\right)=\left\{\mu:\left(\mu^{\prime}, \eta^{\prime}\right)^{\prime} \in \Delta\left(\theta^{b}\right)\right.$, for some $\left.\eta\right\}$. Then, the profile 15 likelihood for $M\left(\theta^{b}\right)$ is

\footnotetext{
${ }^{14}$ Chen et al. (2018) suggest using a sequential Monte Carlo sampler as MCMC may be numerically unstable. We do not experience such problems in our application.
} 


$$
P L_{N}\left(M\left(\theta^{b}\right)\right)=\inf _{\mu \in M\left(\theta^{b}\right)} \sup _{\eta \in H_{\mu}} L_{N}(\mu, \eta)
$$

1 We can now describe the second procedure for a subvector $\mu$ of $\theta$ :

\section{Procedure 2 (subvector)}

${ }_{3}$ (a) draw $B$ samples $\left\{\theta^{(1)}, \ldots, \theta^{(B)}\right\}$ from the posterior distribution $\Pi_{N}$ via a MCMC

$4 \quad$ sampler;

${ }_{5}$ (b) calculate the $(1-\alpha)$ quantile of $\left\{P L_{N}\left(M\left(\theta^{(1)}\right)\right), \ldots, P L_{N}\left(M\left(\theta^{(B)}\right)\right)\right\}$, say $\zeta_{N, \alpha}$;

6 (c) define $\widehat{M}_{\alpha}$ as $\widehat{M}_{\alpha}=\left\{\mu \in M: \sup _{\eta \in H_{\mu}} L_{N}(\mu, \eta) \geq \zeta_{N, \alpha}\right\}$.

7 We now describe a simple procedure for scalar subvectors. Let us define the likelihood 8 ratio

$$
L R_{N}(\theta)=2 N\left(L_{N}(\widehat{\theta})-L_{N}(\theta)\right)
$$

9 for a maximizer $\widehat{\theta}$. Procedure 3 can be implemented in two simple steps

10

11

12

13

${ }_{14}$ As suggested in Chen et al. (2018), the confidence sets are compared to the confidence 15 intervals provided by the standard probit and logit models. 
1

2 Table 2 to Table 9 in this Section contain $95 \%$ confidence intervals obtained using the

4 obtained using Procedure 1 and Procedure 3 of the approach described in Section 5.1 and 5 denoted as CCT1 and CCT3 respectively. Table 2 to Table 7 show estimates considering

6 families with at least one child (i.e. all the families). In addition to that, we conduct our 7 analysis in subsets of the data based on age. Two subsets are considered $6 \leq$ age $\leq 11$

8 (Tables 3, 6) and $12 \leq$ age $\leq 14$ (Tables 4, 7). Moreover, each model is estimated using

9 four sets of covariates. ${ }^{15}$ Table 8 and Table 9 on the other hand, display the estimates of 10 a parsimonious model that includes the number of children as a regressor as well as the 11 average height and weight of adults in the family. Also for these models we consider the 12 age subsets described above. Appendix B shows similar models for families that include 
1 the key covariate, we observe that the presence of other obese children in the family has 2 a positive effect on the probability that a child be obese. This result is robust to all the 3 specifications of the model we considered. The results obtained with the standard binary 4 choice model, either logit or probit, are very similar to the confidence sets computed via 5 CCT3. This may suggest that if there is no point identification, this has only a mild effect 6 on the confidence intervals. The confidence sets obtained via CCT1 are generally larger 7 than those built with CCT3: this is in line with what is suggested in Chen et al. (2018). 8 Furthermore, we find that the effect of obese adults in the family is generally smaller than 9 that of peer children. We also find that by including the genetic proxies and the behavioural 10 variables the confidence sets tend to move to the left and in some cases they include zero. 11 If we look at the results for the two age subsets we notice some differences. However, they 12 may be caused by the difference in sample size. The model specification in Table 8 and 13 Table 9 shows a sizable shift towards the right of the confidence sets associated to the 14 peer effect variable. This result is observed for all age subsets. The confidence sets tend 15 to get larger when we consider the subset of older children; however, also this effect may 16 be caused by the reduced sample size. The effect of the share of obese adults seems to be 17 more ambiguous as it is smaller in comparison with the other model specifications and, for 18 the subset of older children, it includes zero. This result may also depend on the inclusion 19 of average adult weight and height, as they are related to the share of obese adults in the family. As to the variable gender of the child, its effect is significant in almost all the model that the probability of being overweight/obese is larger for males than for females. The child age is insignificant in the quadratic polynomial specification in almost all the model specifications. As to the effect of household consumption expenditures, introduced in the model as a logarithmic transformation, its effect is significant, both for the logit and probit models, either for the standard binary choice model or for the one estimated via CCT3, on the set including all children aged 6-14 years and for the subset of children aged 6-11 years, only when the models do not include other household behavioural variables. In such cases, 
1 the confidence sets are defined in a negative subset of the real line (see columns (1) and

2 (3) in Tables 2, 3, 5, 6) meaning that the probability of being overweight/obese decreases

3 with household consumption expenditures. It thus seems that the impact of consumption

4 expenditures, viewed as a proxy of the economic status of the household, is mediated by

5 the included household and behavioural covariates. One possible interpretation of this

6 result is that those families in better economic conditions can offer better opportunities

7 for a healthy diet and physical activity. On the other hand, resource constraints lead to a

8 lack of opportunities and to a lack of information on the ingredients of a healthy children's

9 diet and on healthy behaviours.

\section{${ }_{10} 6$ Conclusion}

11 This paper contributes to the literature on child obesity by assessing the effect of peers on

12 children's weight outcomes in the context of a narrow peer group. We assessed whether

13 the presence of overweight and obese family members - other children and adults - affects

14 children's weight outcomes. To the best of our knowledge no study has yet analysed the

15 impact of the obesity status of other members of a family on child obesity. We chose to carry out our analysis not presuming point identification for our models. With respect

17 to that aspect, we contribute to the integration, albeit in a rather specific context, of identified models in industrial organization (Blume et al., 2011; Tamer, 2003).

We used a data set on Italian children resulting from statistical matching of the 2012 21 cross sections of two surveys, the Multipurpose Household Survey and the Household 22 Budget Survey, both supplied by ISTAT. To provide valid inference for our partially identified models we use the method proposed by Chen et al. (2018). We found evidence of 24 a strong, positive impact of overweight and obese peer children in the family and of overweight and obese adults on child weight outcomes. Interestingly, in all empirical models we

26 find that the impact of overweight and obese peer children in the household is larger than 


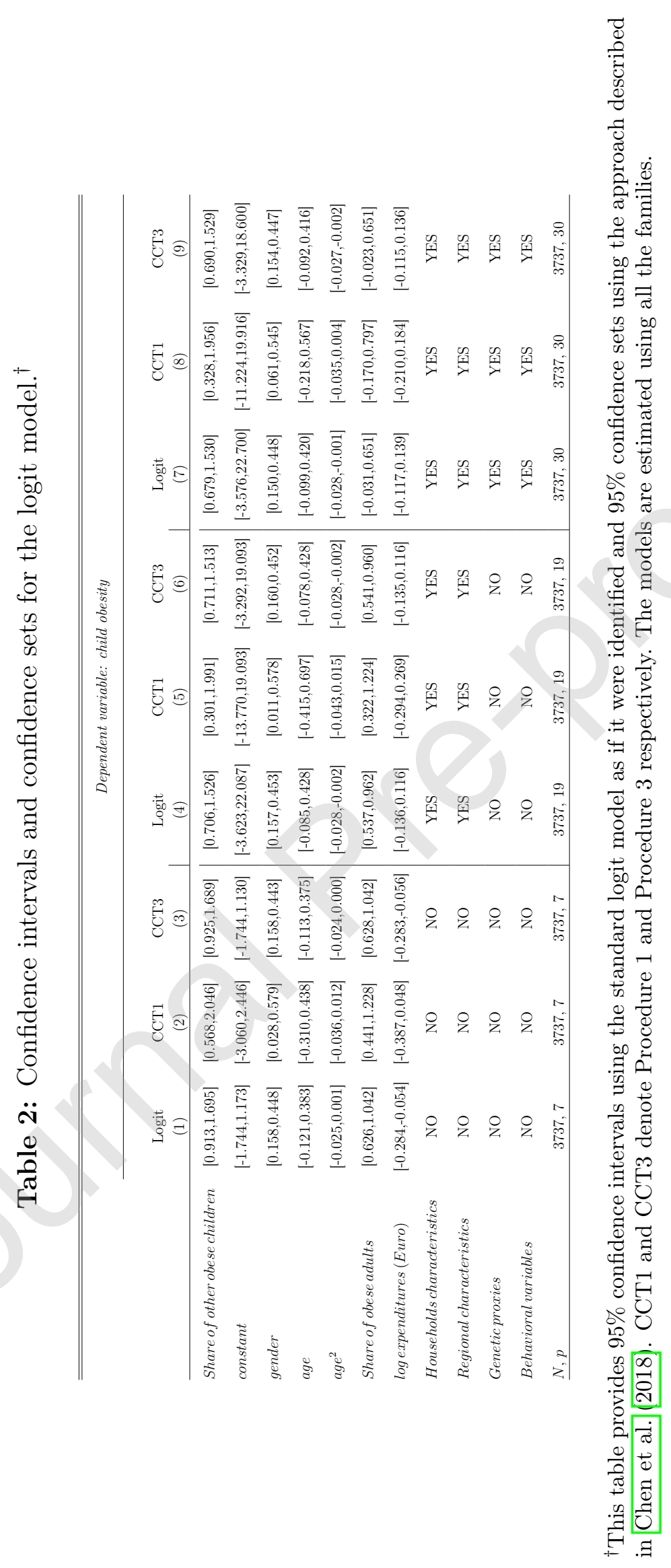




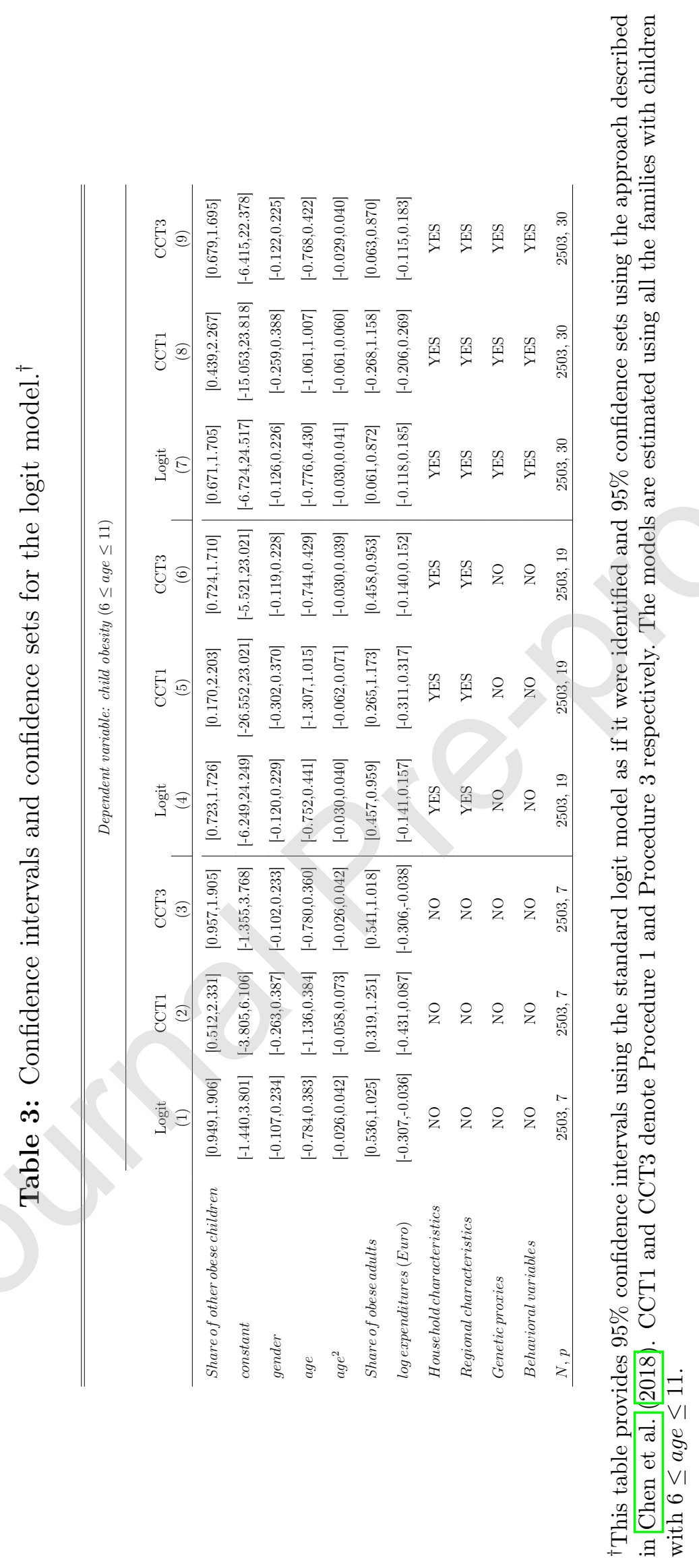




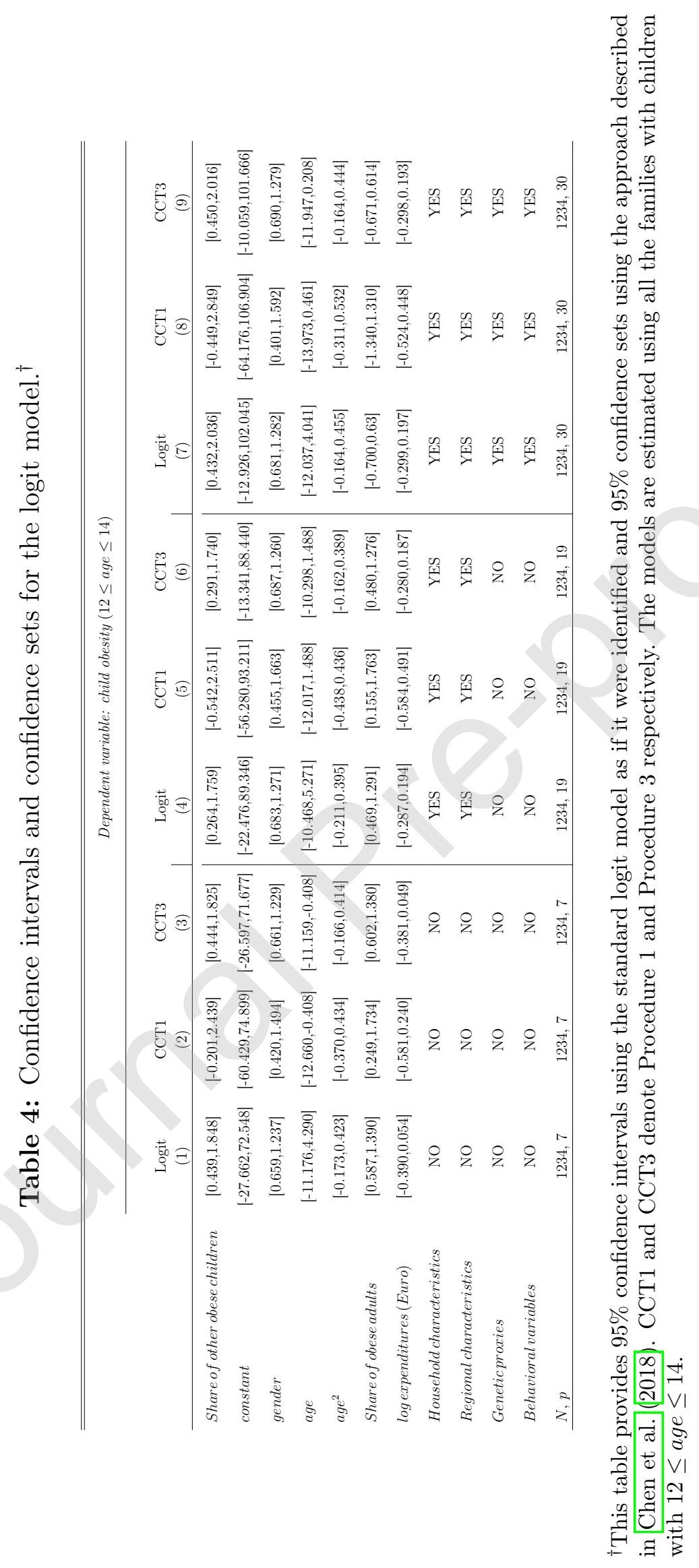




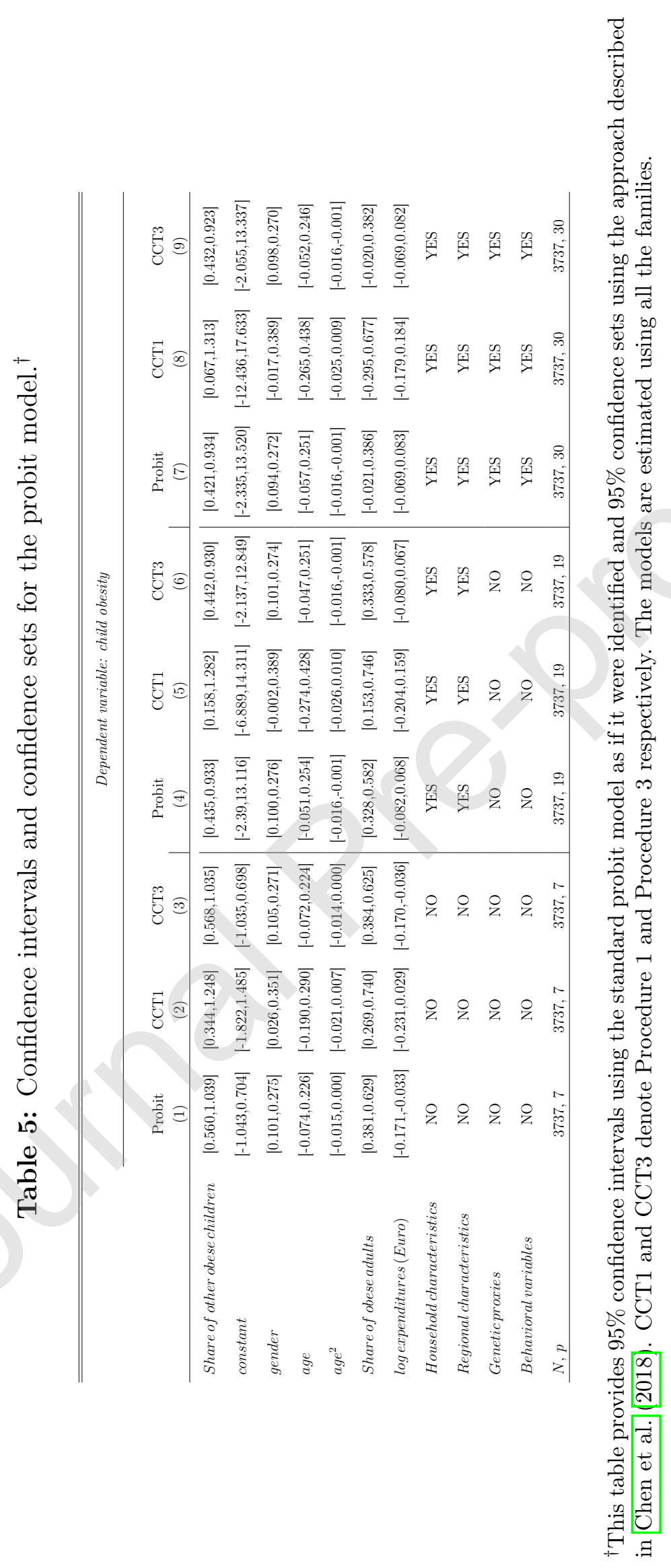




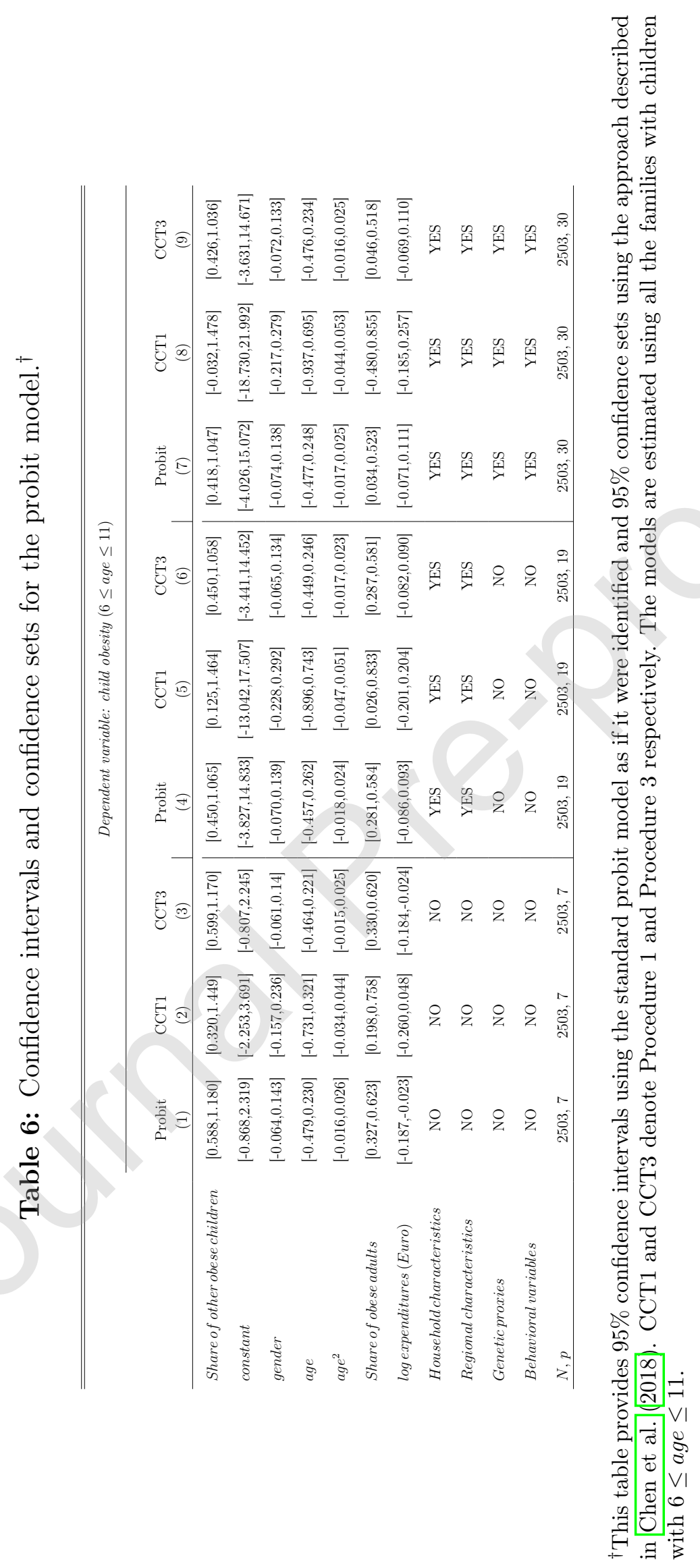




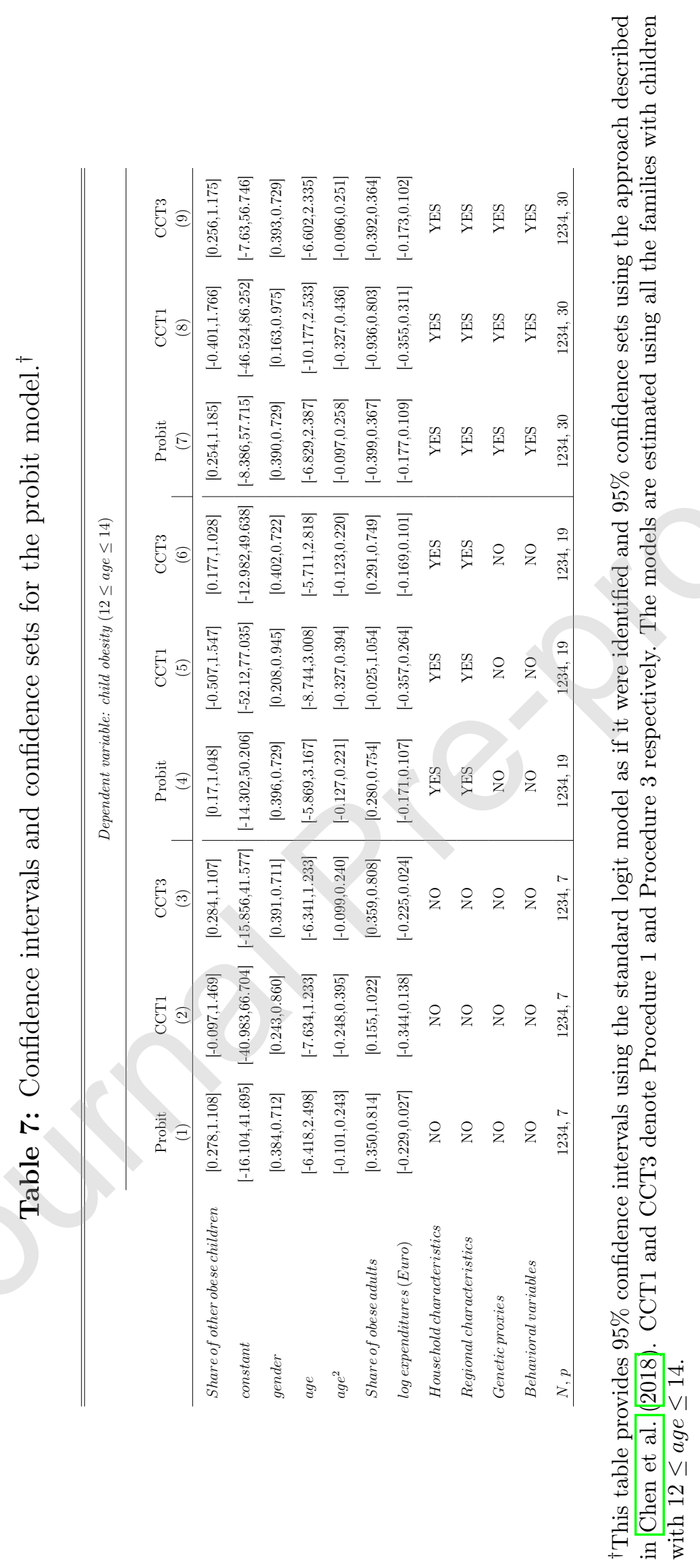




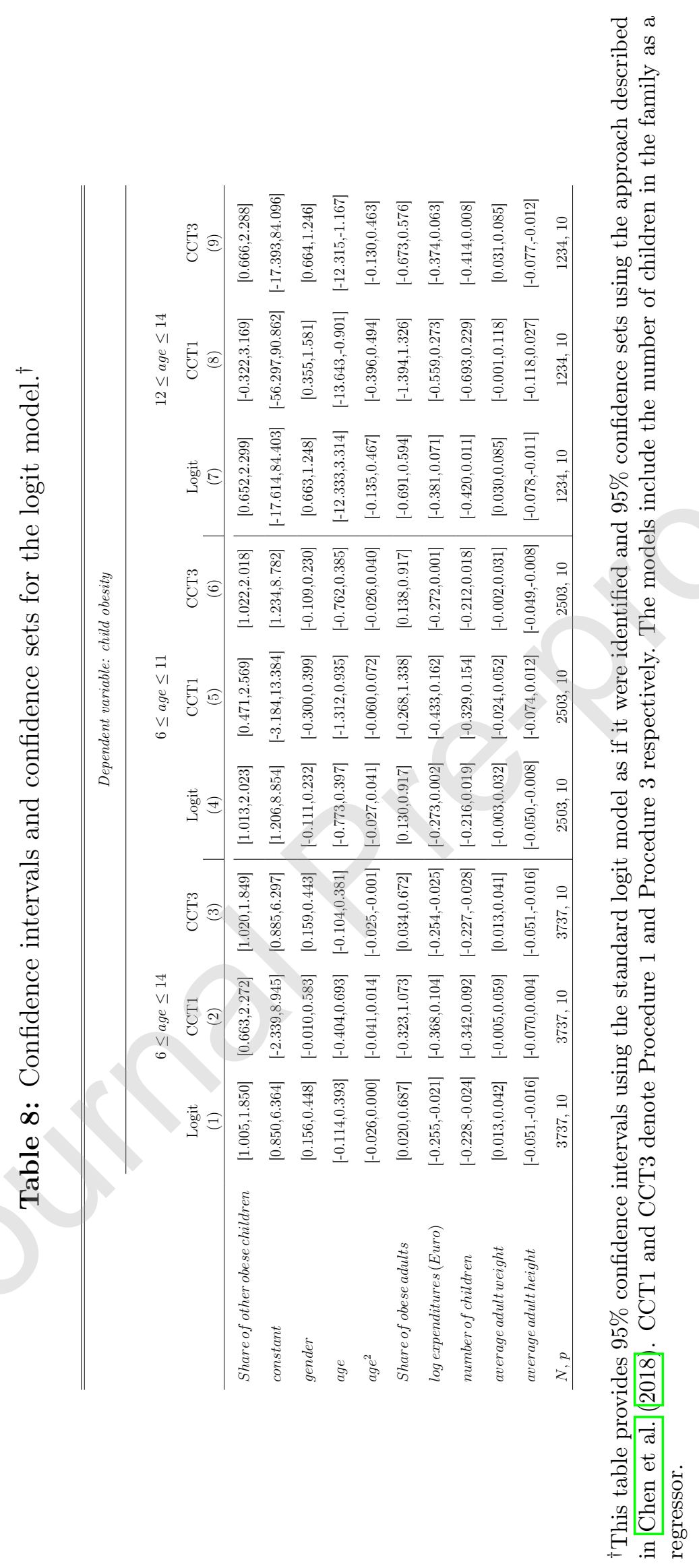




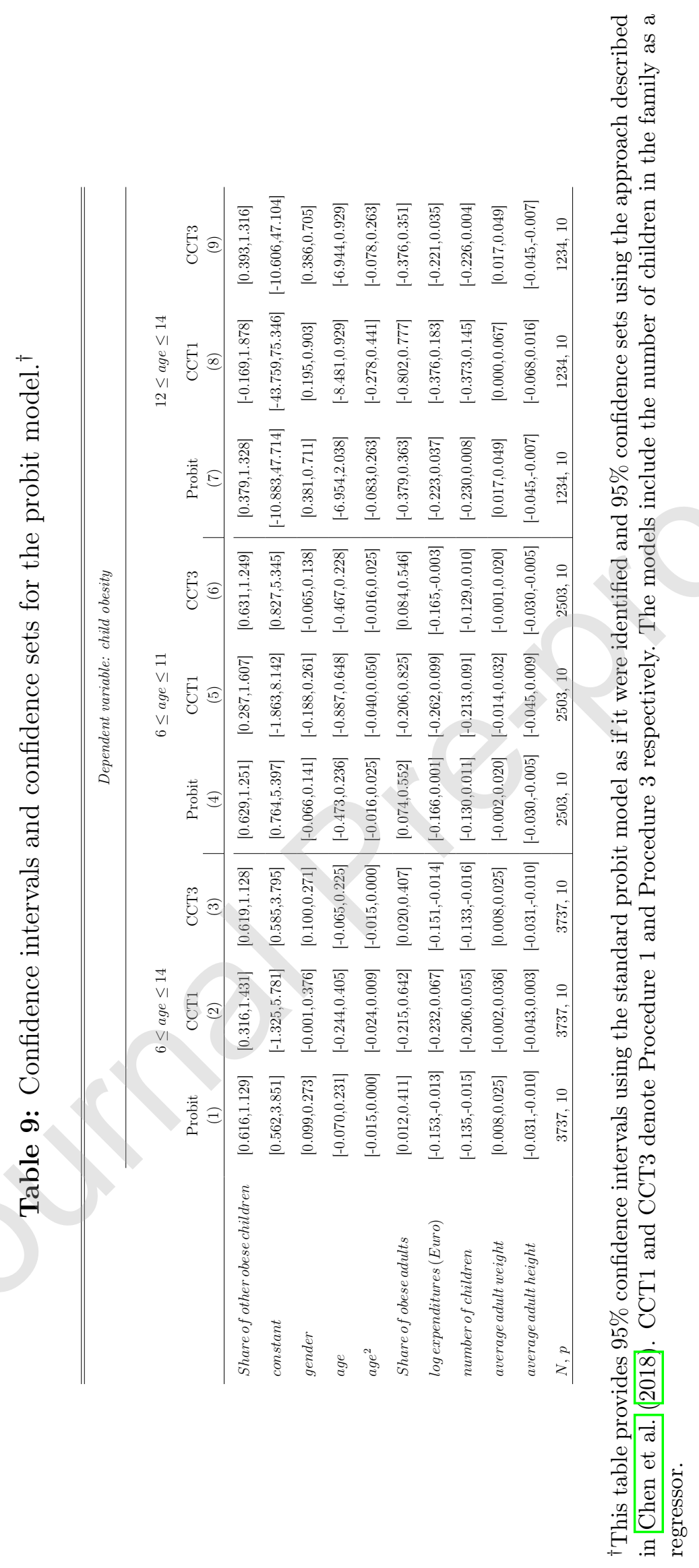


1 the impact of adults. We also find that, when genetic proxies and behavioral variables are 2 added, the impact of the presence of overweight and obese adults is driven to zero while the 3 impact of overweight and obese peer children remains positive. Our results are consistent 4 with studies on child imitation behaviour and the role model age Zmyj, Ascherslebel et 5 al. 2012; Zmyj, N. Daum et al., 2012; Zmyj \& Seehagen, 2013), where prolonged contact 6 with peers led children to imitate peers more than adults.

7 Despite growing rates of child obesity, empirical evidence on the factors affecting Italian 8 child weight outcomes remains poor. Further exploration of causal pathways linking social 9 interaction within the family and child obesity is therefore desirable. We show that the 10 presence overweight/obese parents and/or peer siblings is an important factor affecting 11 child obesity in Italy. In particular, we show that the presence of other overweight and obese 12 children in the family is the most important factor affecting child obesity. Indeed, when 13 the richest model specification is used, i.e. when we include proxies for genetic variables ${ }_{14}$ (columns 7, 8, 9 in Tables 2, 4, 5, 7), the share of obese adults is no longer significant, 15 while the peer effect variable is still significant. This result suggests that within-the-family obesity is driven more by peer siblings interaction than by interactions between the parent 17 and the child. In general, it seems that family characteristics and behaviours affect children 18 habits and their probability of being obese. In this context, family-based programmes, 19 based on collaborative approaches, may help preventing child obesity. Particular attention 20 should be paid to households with more than one overweight child where a collaborative ${ }_{21}$ approach could have much more impact. Moreover, since siblings relationships are the 22 longest lasting ones, the use of a true family-based approach in taking action against 23 childhood obesity will increase the likelihood that changes in child health behaviours will 24 be sustainable (see, e.g., Berge \& Everts, 2011). 


\section{${ }_{25}$ References}

1 Asirvatham, J., Nayga, R. M., Jr. \& Thomsen, M. R. (2014). Peer-effects in obesity among

2 public elementary school children: A grade-level analysis. Applied Economic Perspectives

$3 \quad$ and Policy, 36(3), 438-459.

4 Berge, J. M. \& Everts, J. C. (2011). Family-based interventions targeting childhood 5 obesity: a meta-analysis. Childhood Obesity, 7(2), 110-121.

6 Binkin, N., Fontana, G., Lamberti, A., Cattaneo, C., Baglio, G., Perra, A. \& Spinelli, A.

7 (2010). A national survey of the prevalence of childhood overweight and obesity in Italy.

$8 \quad$ Obesity Reviews, 11(1), 2-10.

9 Black, S., Breining, S., Figlio, D., Guryan, J., Karbownik, K., Skyt Nielsen, H., ... Simonsen, M. (2017). Sibling spillovers (Working Papers No. 23062). National Bureau of

$11 \quad$ Economic Research.

12 Blume, L. E., Brock, W. A., Durlauf, S. N. \& Ioannides, Y. M. (2011). Identification of 13 social interactions. In Handbook of social economics (Vol. 1, pp. 853-964).

14 Blume, L. E. \& Durlauf, S. N. (2006). Identifying social interactions: A review. In J. Oakes 15 \& S. Kaufmann (Eds.), Methods in social epidemiology (pp. 287-315). Wiley.

${ }_{16}$ Bracale, R., Milani, L., Ferrara, E., Balzaretti, C., Valerio, A., Russo, V., .. Carruba, 17 M. O. (2013). Childhood obesity, overweight and underweight: a study in primary 18 schools in milan. Eating and Weight Disorders - Studies on Anorexia, Bulimia and Obesity, 18(2), 183-191.

Brilli, Y., Del Boca, D. \& Pronzato, C. (2016). Does child care availability play a role

21 in maternal employment and children's development? Evidence from Italy. Review of 22 Economics of the Household, 14(1), 27-51.

23 Brock, W. A. \& Durlauf, S. N. (2001). Discrete choice with social interactions. The Review of Economic Studies, 68(2), 235-260. 
25

1

4 Cawley, J. \& Meyerhoefer, G. (2012). The medical care costs of obesity: an instrumental 5 variables approach. Journal of Health Economics, 31(4), 210-230.

6 Champion, S. L., Rumbold, A. R., Steele, E. J., Giles, L. C., Davies, M. J. \& Moore, V. M. 7 (2012). Parental work schedules and child overweight and obesity. International Journal 8 of Obesity, 36, 573-580.

9 Chen, X., Christensen, T. M. \& Tamer, E. (2018). Monte carlo confidence sets for identified

Brock, W. A. \& Durlauf, S. N. (2007). Identification of binary choice models with social interactions. Journal of Econometrics, 140(1), 52-75.

Cawley, J. \& Liu, F. (2012). Maternal employment and childhood obesity: A search for mechanisms in time use data. Economics and Human Biology, 10(4), 352-364.

sets. Econometrica, 86(6), 1965-2018.

Christakis, N. A. \& Fowler, J. H. (2007). The spread of obesity in a large social network over 32 years. The New England Journal of Medicine, 357, 370-379.

Cole, T. J., Bellizzi, M. C., Flegal, K. M. \& Dietz, W. H. (2000). Establishing a standard definition for child overweight and obesity worldwide: international survey. British Medical Journal, 320(7244), 1240.

Dishion, T. J. \& Tipsord, J. M. (2011). Peer contagion in child and adolescent social and emotional development. Annual Review of Psychology, 62(1), 189-214.

Dustan, A. (2018). Family networks and school choice. Journal of Development Economics, $134,372-391$.

Fadlon, I. \& Nielsen, T. (2019). Family health behaviors. American Economic Review, $109(9), 3162-3191$.

Fertig, A., Glomm, G. \& Tchernis, R. (2009). The connection between maternal employment and childhood obesity: inspecting the mechanisms. Review of Economics of the Household, 7(3), 227-255. 
${ }_{25}$ Fletcher, J., Hair, N. \& Wolfe, B. (2012). Am I my brother's keeper? Sibling spillover

1 effects: the case of developmental disabilities and externalizing behavior (Working Papers

$2 \quad$ No. 18279). National Bureau of Economic Research.

3 Fowler, J. \& Christakis, N. (2008). Estimating peer effects on health in social networks:

$4 \quad$ A response to Cohen-Cole and Fletcher; and Trogdon, Nonnemaker, and Pais. Journal 5 of Health Economics, 27(5), 1400-1405.

6 Gaina, A., Sekine, M., Chandola, T., Marmot, M. \& Kagamimori, S. (2009). Mother

7 employment status and nutritional patterns in Japanese junior highschool children. In$8 \quad$ ternational Journal of Obesity, 33(7), 753-757.

9 García, E., Labeaga, J. M. \& Masagué, A. C. O. (2006, July). Maternal Employment and Childhood Obesity in Spain (Working Papers No. 2006-17). FEDEA.

11 Graham, B. S. (2008). Identifying social interactions through conditional variance restrictions. Econometrica, $76(3), 643-660$. 
25 Heissel, J. A. (2019). Teen fertility and siblings' outcomes: Evidence of family spillovers

$1 \quad$ using matched samples. Journal of Human Resources. (Published ahead of print April

$2 \quad$ 10, 2019 doi:103368/jhr.56.1.0218-9341R2)

3 Herbst, C. M. \& Tekin, E. (2011). Child care subsidies and childhood obesity. Review of

$4 \quad$ Economics of the Household, 9(3), 349-378.

5 Hubbard, M. (2008). The effect of mothers' employment and child care decisions on the

6 body mass status of young children. The University of North Carolina at Chapel Hill

$7 \quad$ Working Paper.

8 Joensen, J. \& Nielsen, H. (2018). Spillovers in education choice. Journal of Public Eco-

$9 \quad$ nomics, $157,158-183$.

10 Kinge, J. (2016). Body mass index and employment status: a new look. Economics and $11 \quad$ Human Biology, 22, 117-125.

12 Krauth, B. (2006). Social interactions in small groups. Canadian journal of Economics, $13 \quad 414-433$.

14 Lauria, L., Spinelli, A., Buoncristiano, M. \& Nardone, P. (2019). Decline of childhood over15 weight and obesity in italy from 2008 to 2016: results from 5 rounds of the population16 based surveillance system. BMC Public Health, 19(618), 1-9.

${ }_{17}$ Liu, E., Hsiao, C., Matsumoto, T. \& Chou, S. (2009). Maternal full-time employment 18 and overweight children: Parametric, semi-parametric, and non-parametric assessment. 19 Journal of Econometrics, 152(1), 61-69.

2o Llewellyn, A., Simmonds, M., Owen, C. \& Woolacott, N. (2016). Childhood obesity as 21 a predictor of morbidity in adulthood: a systematic review and meta-analysis. Obesity $22 \quad$ Reviews, 17, 56-67. 
${ }_{23}$ Lobstein, T., Jackson-Leach, R., Moodie, M. L., Hall, K. D., Gortmaker, S. L., Swinburn,

$1 \quad$ B. A., ... McPherson, K. (2015). Child and adolescent obesity: part of a bigger picture.

$2 \quad$ The Lancet, 385(9986), 2510-2520.

3 Manski, C. F. (1993). Identification of endogenous social effects: The reflection problem.

$4 \quad$ The review of economic studies, 60(3), 531-542.

5 Manski, C. F. (2003). Partial identification of probability distributions. Springer Science $6 \quad \&$ Business Media.

7 Molinari, F. (in press). Econometrics with partial identification. Handbook of economet8 rics.

9 Mora, T. \& Gil, J. (2013). Peer effects in adolescent BMI: evidence from Spain. Health $10 \quad$ Economics, 22(5), 501-516.

11 Morrill, M. S. (2011). The effects of maternal employment on the health of school-age children. Journal of Health Economics, 30 (2), 240-257.

13 Nicoletti, C. \& Rabe, B. (2019). Siblings spillover effects in school achievement. Journal 14 of Applied Econometrics, 34, 482-501.

15 Nie, P., Sousa-Poza, A. \& He, X. (2015). Peer effects on childhood and adolescent obesity 16 in China. China Economic Review, 35, 47-69.

${ }_{17}$ Powell, K., Wilcox, J., Clonan, A., Bissell, P., Preston, L., Peacock, M. \& Holdsworth, M. 18 (2015). The role of social networks in the development of overweight and obesity among 19 adults: a scoping review. BMC Public Health, 15(1), 996.

Qureshi, J. (2018). Siblings, teachers, and spillovers on academic achievement. Journal of Human Resources, 53, 272-297.

22 Renna, F., Grafova, I. \& Thakur, N. (2008). The effect of friends on adolescent body weight. Economics and Human Biology, 6(3), 377-387. 
24

5 Trogdon, J. G., Nonnemaker, J. \& Pais, J. (2008). Peer effects in adolescent overweight.

$6 \quad$ Journal of Health Economics, 27(5), 1388-1399.

7 UNICEF. (2019). The state of the world's children 2019. children, food and nutrition.

$8 \quad$ growing well in a changing world.

9 Wardle, J., Carnell, S., Hawhort, C. \& Plomin, R. (2008). Evidence for a strong ge-

Schwartz, D. L., Chase, C. C., Oppezzo, M. A. \& Chin, D. B. (2011). Practicing versus inventing with contrasting cases: The effects of telling first on learning and transfer. Journal of Educational Psychology, $103(4), 759$.

Tamer, E. (2003). Incomplete simultaneous discrete response model with multiple equilibria. The Review of Economic Studies, 70(1), 147-165.

Wardle, J., Carnell, S., Hawhort, C. \& Plomin, R. (2008) Evidene for a strong genetic influence on childhood adiposity despite the force of the obesogenic environment. American Journal of Clinical Nutrition, 87, 398-404.

Yajuan, L., Palma, M. A., Towne, S. D., Warren, J. L. \& Ory, M. G. (2016). Peer effects on childhood obesity from an intervention program. Health Behavior and Policy Review, 3, 323-335.

Yi, J., Heckman, J., Zhang, J. \& Conti, G. (2015). Early health shocks, intra-household resource allocation and child outcomes. The Economic Journal, 125, F347-F371.

Zmyj, N., Ascherslebel, G., Prinz, W. \& Daum, M. (2012). The peer model advantage in infants' imitation of familiar gestures performed by differently aged models. Frontiers in Psychology, 3, 1-7.

Zmyj, N., N. Daum, M., Prinz, W., Nielsen, M. \& Ascherslebel, G. (2012). Fourteenmonths-old's imitation of differently aged models. Infant and Child Development, 21, $250-266$.

Zmyj, N. \& Seehagen, S. (2013). The role of a model's age for the young children's imitation: a research review. Infant and Child Development, 22, 622-641. 


\section{. Appendix for "Family Ties and Child Obesity in Italy"}

2

\author{
Federico Crudu* \\ University of Siena and CRENoS
}

\author{
Laura Neri ${ }^{\dagger}$ \\ University of Siena
}

Silvia Tiezzi $\ddagger$

University of Siena

October 2020

\section{${ }_{4}$ Appendix A Statistical Matching}

5 Matching procedures impute the target variables from a donor to a recipient survey. In

6 the basic framework SM integrates two data sources $\mathcal{A}$ and $\mathcal{B}$ drawn from the same target

7 population (Cohen, 1991; Radner et al., 1980; Rodgers, 1984). $\mathcal{A}$ contains vector-valued

8 variables $(X, Y)$, whereas $\mathcal{B}$ contains vector-valued variables $(X, Z)$ such that $X$ is shared

9 by both sources. The $X$ variables common to both surveys are used as a bridge to create

10 records containing $(X, Y, Z)$ which can then be used to investigate the relationship between

$11 \quad Y$ and $Z$ (D'Orazio et al., 2006). Our purpose was to integrate households' total current

12 consumption expenditure from the HBS (denoted survey $\mathcal{A}$ ) into the MSH dataset (survey

$13 \mathcal{B})$.

${ }_{14}$ The first step was to identify the vector of matching variables $X$. Since $\mathcal{A}$ and $\mathcal{B}$

15 are representative samples of the same population, the common variables are expected to

16 share the same marginal/joint distribution. This check was performed using the Cramer's

$17 V$ association measures. Potentially, all the variables identified and chosen according to this

18 check could be used. In actual fact, only the most relevant ones were identified and selected

\footnotetext{
${ }^{*}$ Department of Economics and Statistics, University of Siena, Piazza San Francesco, 7/8 53100 Siena, federico.crudu@unisi.it.

${ }^{\dagger}$ Department of Economics and Statistics, University of Siena, Piazza San Francesco, 7/8 53100 Siena, laura.neri@unisi.it.

${ }_{\ddagger}^{\ddagger}$ Department of Economics and Statistics, University of Siena, Piazza San Francesco, 7/8 53100 Siena, silvia.tiezzi@unisi.it.
} 
1 according to a linear model for predicting the logarithm of total current consumption

2 expenditure, our target variable. Table A1 shows the set of matching variables used to

3 predict/impute the target variable. The listed common variables explained $70 \%$ of the

4 total variability of the target variable. In addition to these, we included a number of

5 interaction terms in the specification.

Table A1: Final matching variables.

\begin{tabular}{ll}
\hline Northwest & Household living in the North West \\
Northeast & Household living in the North East \\
Central & Household living in the Centre \\
Single_parent & Family type: single parent \\
Parents_both & Family type: both parents \\
Singleton & Family type: Single \\
Household size & Household size \\
\#_members0_5 & \# persons 0-5 years old \\
\#_members6_17 & \# persons 6-17 years old \\
\#_members18_34 & \# persons 18-34 years old \\
\#_members35_65 & \# persons 35-65 years old \\
Gender_RP & Gender of the reference person \\
Mstatus_RP & Marital status of the reference person \\
Employment_RP & Professional position of the reference person \\
Home & Home ownership \\
Rooms & \# of rooms \\
Ec_resource & Adequacy of economic resources \\
CPI & Consumer Price Index at the regional level \\
CPI_food & Food Price Index at the regional level \\
\hline \hline
\end{tabular}

$6 \quad$ The next step was imputation from the donor to the recipient. The chosen imputation 7 method was the Sequential Regression Multiple Imputation (Raghunathan et al., 2001) 8 implemented through IVEware software that enables imputation of missing data in the 9 recipient variables and in the set of matching variables. IVEware has a number of desirable 10 properties that make it particularly well suited for imputing missing data in large datasets.

11 For example, imputation models can be specified according to the nature of the variable to 12 be imputed. The software easily handles arbitrary missing data patterns with categorical 13 and continuous variables. Finally, a sequential method is used to impute missing values: 14 the variable with the least amount of missing data is imputed first and then used in sub- 
1 sequent imputations; the next variable with the second least amount of missing data is

2 then imputed and used in subsequent imputations. The resulting quality of the match-

3 ing can be assessed by comparing the marginal distribution of the target variable in the

4 observed data (i.e. in the donor dataset) and in the dataset obtained from the matching.

5 The distributions of the observed and imputed data were very close (see Figure A1) given

6 the high explanatory power of the predictors included in the model of the target variable.

7 This closeness increased the reliability of the statistical matching. In addition, it reduced

8 the problem of conditional independence (CI), a required hypothesis for the validity of SM.

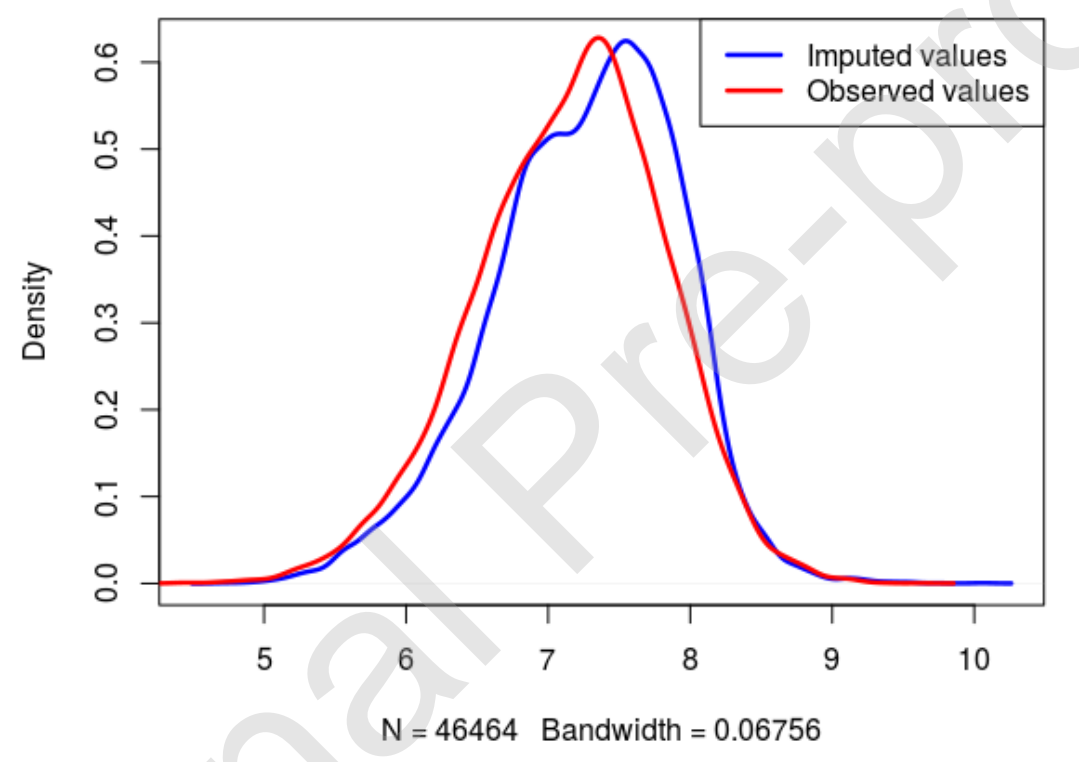

Figure A1: Probability density function of the observed target variable (log expenditure) from the HBS survey (2012) and probability density function of the imputed target variable in the final dataset.

9 The $\mathrm{CI}$ condition implies that, given three random variables $(X, Y, Z)$ and the model 10 defined by $(X Y, X Z)$, any relationship between $Y$ and $Z$ can be explained by the set of 11 matching variables $X$.

12 In our study, the CI condition implied that any existing relationship between $Y$ (house13 hold consumption expenditure) and $Z$ (the binary indicator of child obesity) can be ex14 plained by the set of matching variables $X$. In other words, $Y$ and $Z$ may appear to be 
1 related if $X$ is not considered. In order to meet this assumption, a third data set with 2 complete information on $(X, Y, Z)$ is needed. Since this dataset is normally not available,

3 we checked the CI assumption using a variable that expresses a subjective evaluation re-

4 garding the household's economic condition (Ec_resource, introduced in Table A1) as a

5 proxy for the household's total consumption expenditure. This is a binary indicator equal

6 to 1 if the household's economic condition is considered to be "very good" or "adequate" 7 and equal to 0 if it is "scarce" or "absolutely insufficient".

$8 \quad$ The odds ratio of the logit model for obesity given Ec_resource indicated a statistic9 ally significant relationship (see column 1 in Table A2), implying that good or adequate 10 economic resources at household level reduce the probability of child obesity. In Table A2 11 column 2 we consider a second model including Ec_resource and a subset of our match12 ing variables as explanatory variables. All covariates were significant, but the variable 13 Ec_resource had an odds ratio close to one implying a statistically insignificant effect on 14 obesity. A similar check was conducted considering Ec_resource as the dependent vari15 able and the obesity binary indicator as an independent variable, obtaining similar results ${ }_{16}$ 1. We are therefore confident that the CI assumption is not violated.

\section{${ }_{17}$ Appendix B Robustness Checks}

18 This Section collects the results for the full set of parameters and the robustness checks 19 as described in Section 5.2. In particular, Tables B1 and B10 show results for the whole 20 sample, while Tables B2 and B11 and Tables B3 and B12 consider families with $6 \leq a g e \leq$ $21 \quad 11$ and $12 \leq$ age $\leq 14$ respectively. We consider similar subsets of data for families that 22 have more than one child (see Tables B4 and B13 for the age group $6 \leq$ age $\leq 14$, Tables ${ }_{23}$ B5 and B14 for the age group $6 \leq a g e \leq 11$ and Tables B6 and B15 for the age group ${ }_{24} 12 \leq$ age $\left.\leq 14\right)$. The last subset of data considers families with only one child. The ${ }_{25}$ corresponding results are found in Tables B7 and B16 for the age group $6 \leq$ age $\leq 14$,

\footnotetext{
${ }^{1}$ Available from the authors on request.
} 
Table A2: Check on the CI assumption. ${ }^{\dagger}$

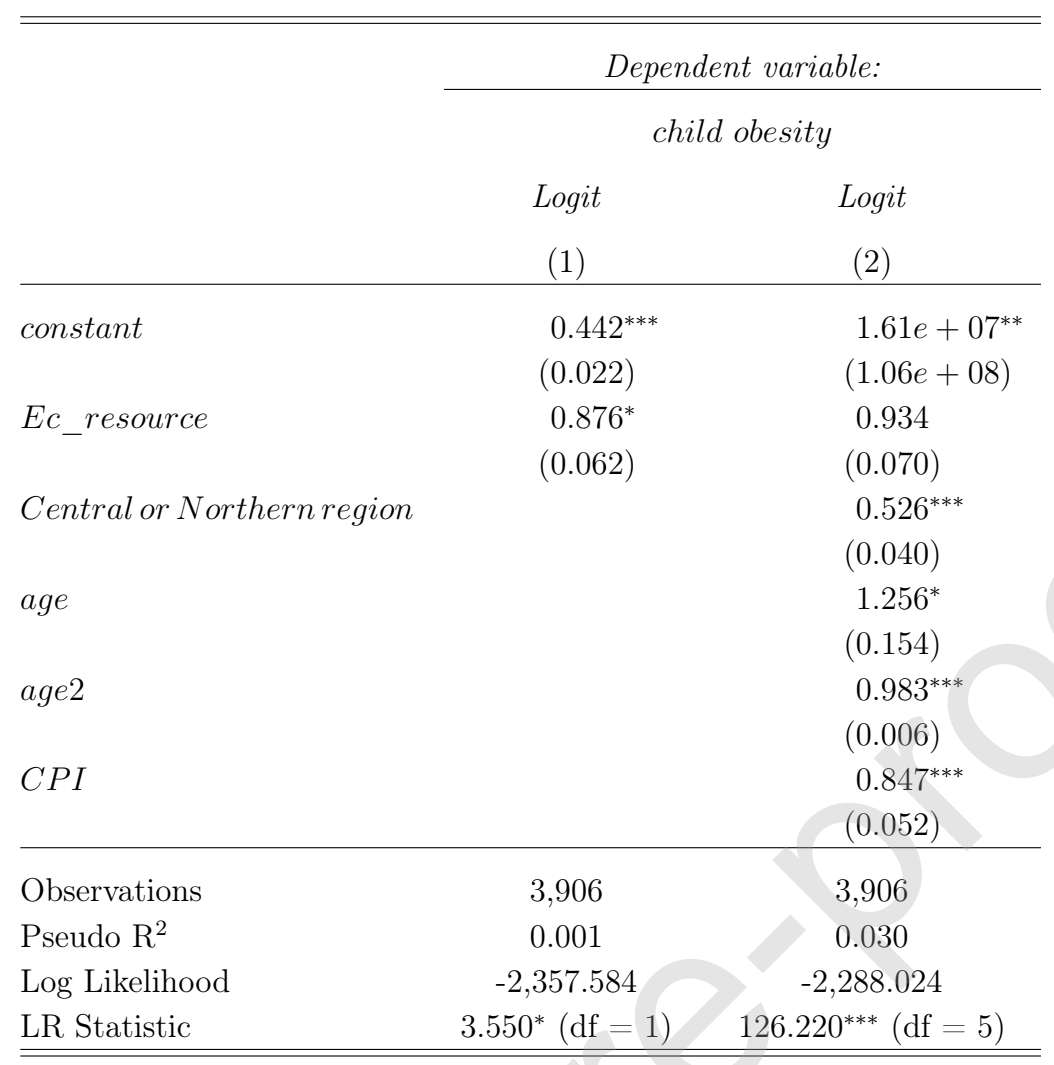

${ }^{\dagger}$ Standard errors in parentheses; ${ }^{*} \mathrm{p}<0.1 ;{ }^{* *} \mathrm{p}<0.05 ;{ }^{* * *} \mathrm{p}<0.01$.

1 Tables B8 and B17 for the age group $6 \leq a g e \leq 11$ and Tables B9 and B18 for the age group

$212 \leq$ age $\leq 14$. If peers imitation increases with prolonged peer contact we should observe,

3 as we do, a smaller peer effect for the second sub-group $(12 \leq a g e \leq 14)$ as pre-adolescents

4 spend more time than their younger counterpart outside the family environment. It is

5 worth noticing that some specifications display some issues of multicollinearity. For such

6 a reason in some cases we drop one regressor (Tables B6, B7, B8, B15, B16, B17) or two

7 regressors (Tables B9 B18).

$8 \quad$ In addition, we consider a fixed effect approach where families are clustered in a restric-

9 ted number of groups. The number of groups is chosen a priori (10 and 20) and for each

10 group we introduce a dummy variable. The clusterisation is based on the characteristics

11 of the adults in terms of occupational status, mother's education, presence of diabetes or

12 chronic diseases, some characteristics about eating behaviours and the number of individu- 
1 als in the family. Since most variables involved are binary we cannot use, for example,

2 standard $k$-means algorithms. Hence, we resort to apply an approach that works for mixed

3 data types based on Huang's $k$-prototypes algorithm (Szepannek, 2018). The results, re-

4 ported in Table B19 and Table B20. match to a large extent the results displayed in the 5 main text. 


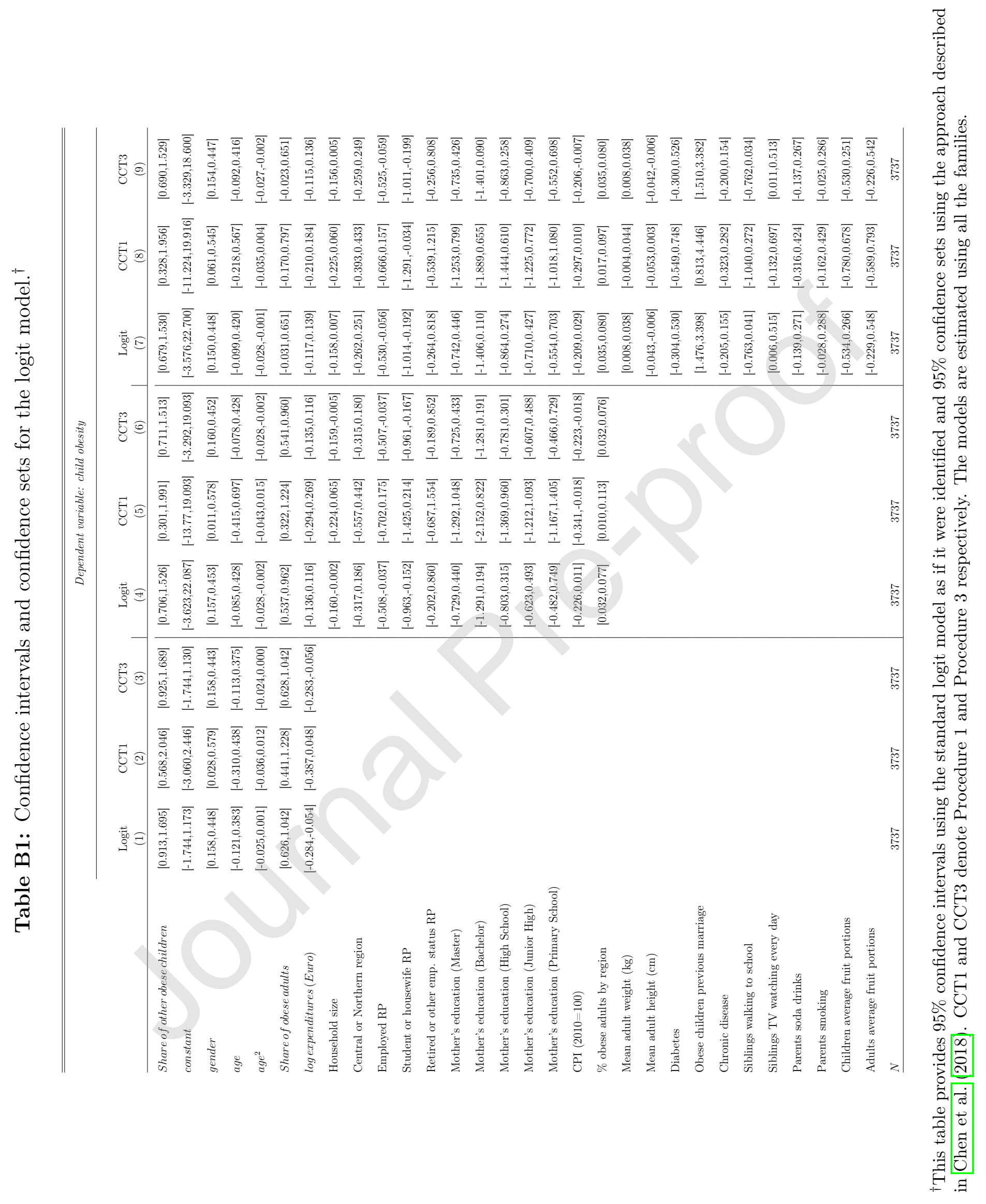




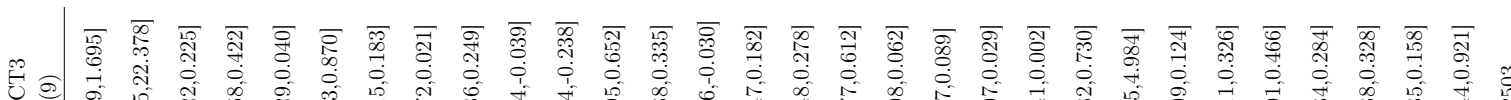

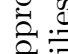

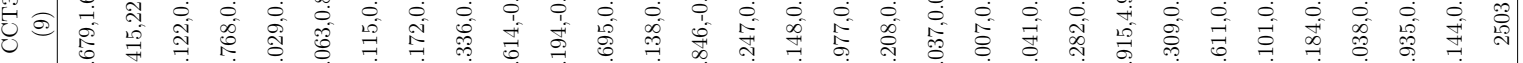

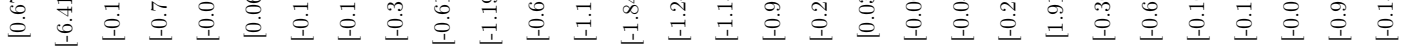

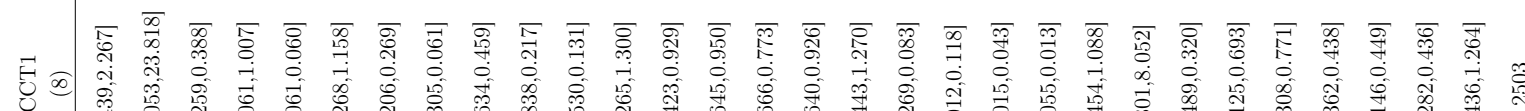
s.

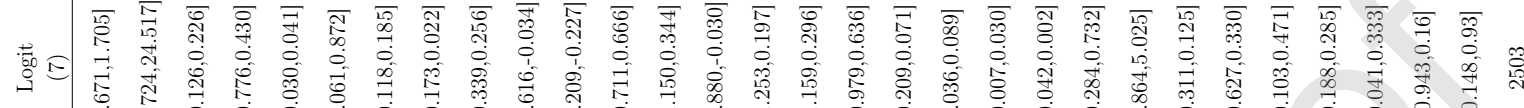
奥 尊

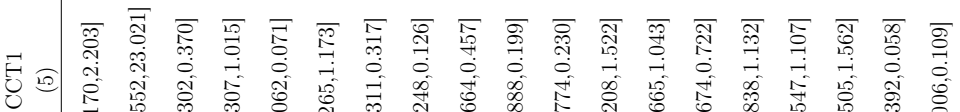

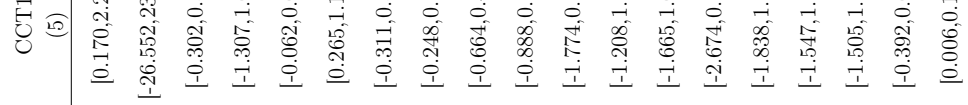

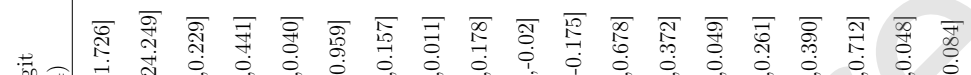

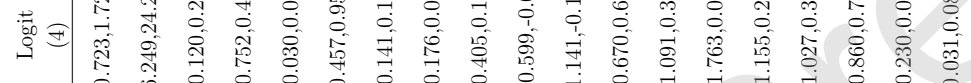

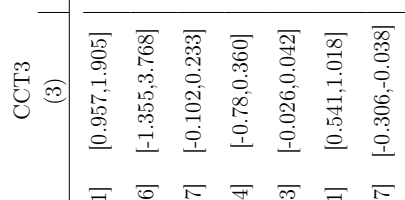

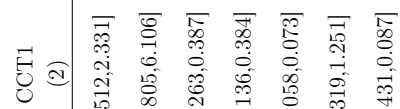
败

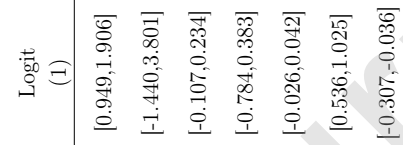

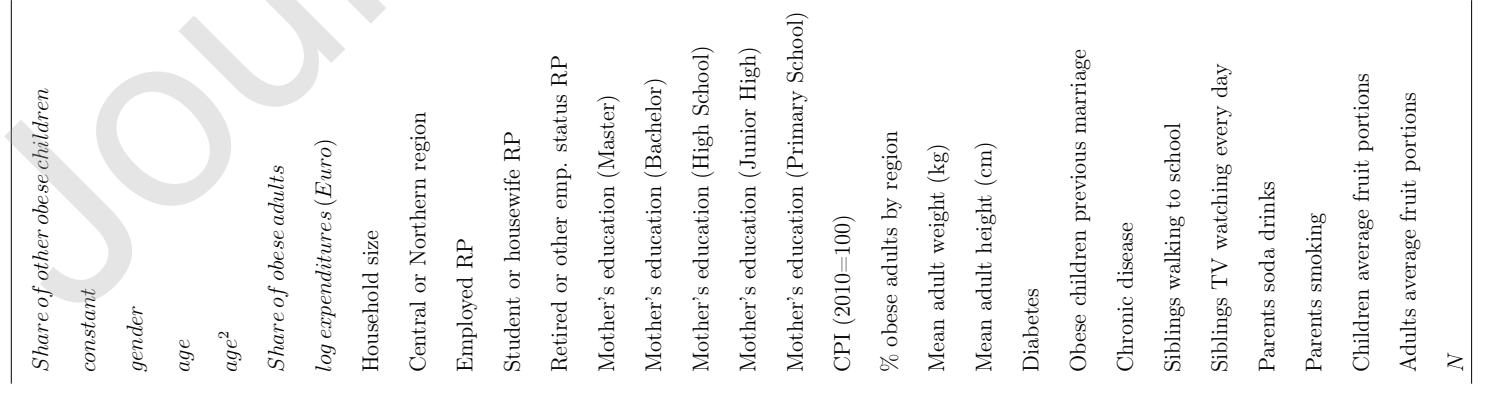




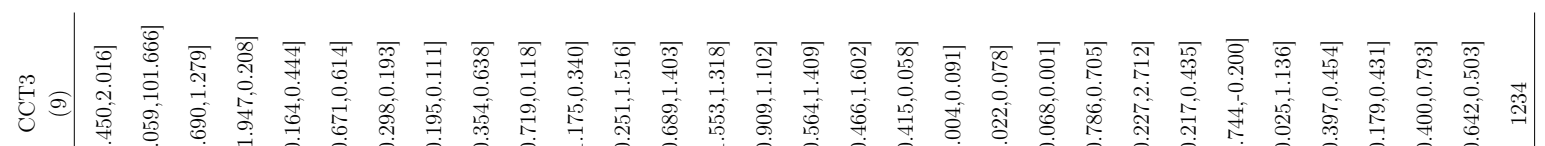

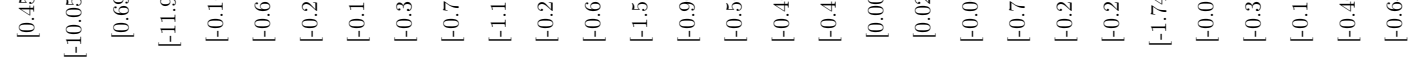

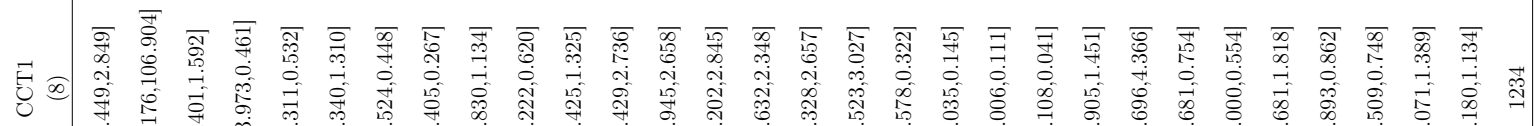

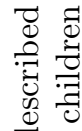

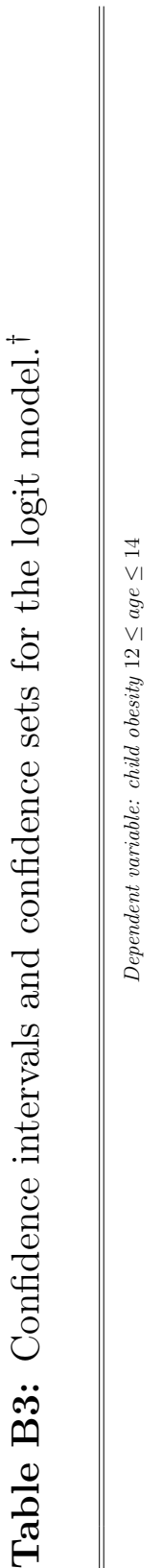

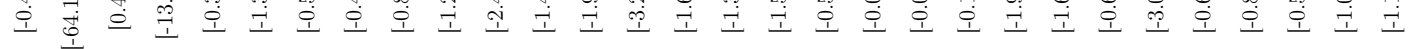

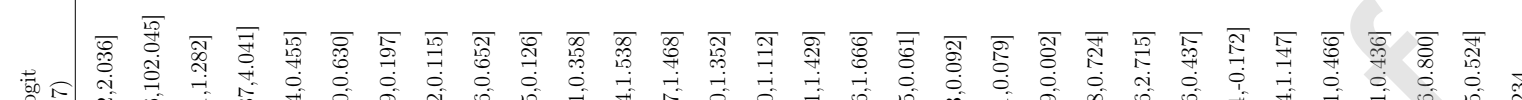

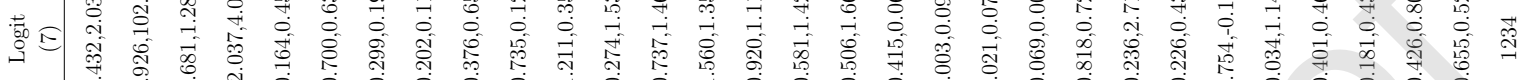

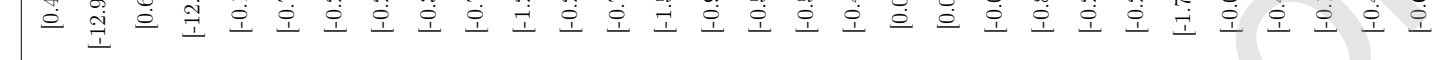

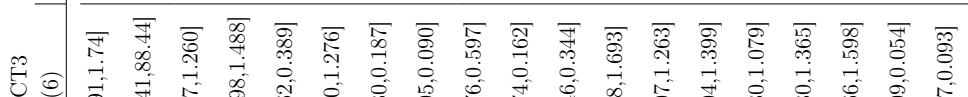

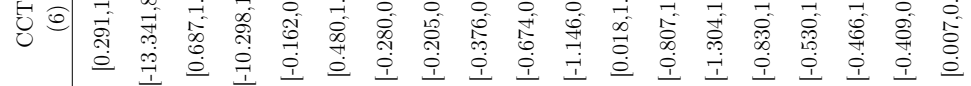

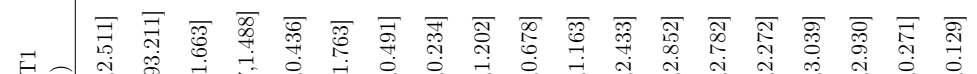

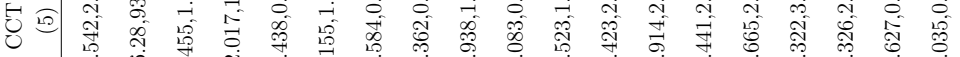

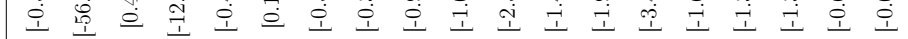

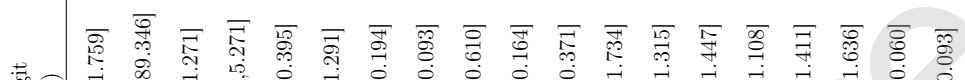

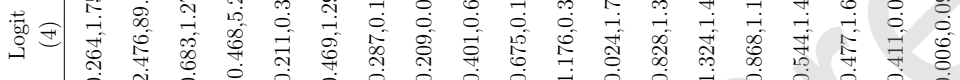

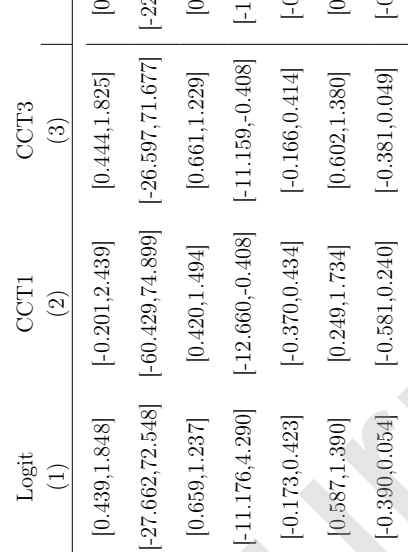

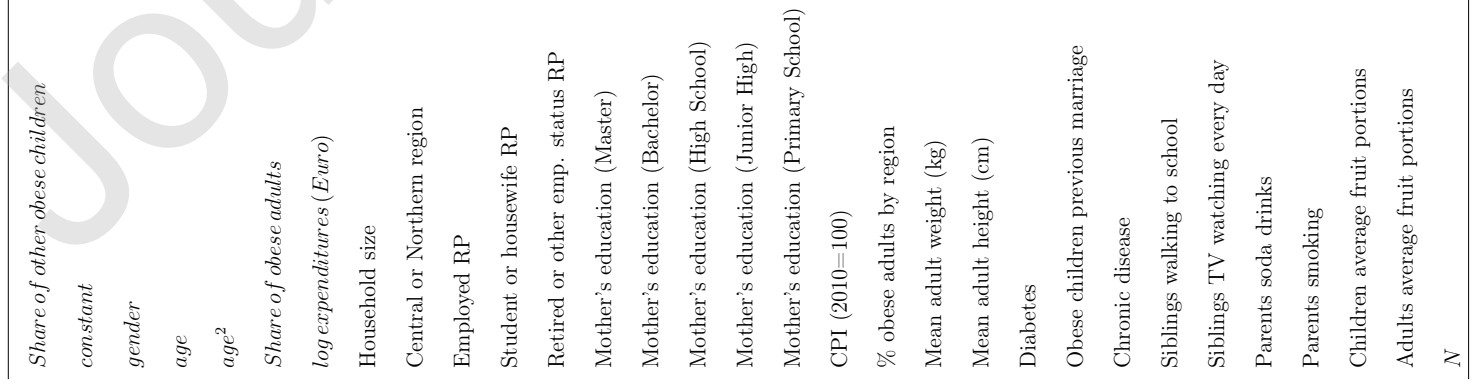




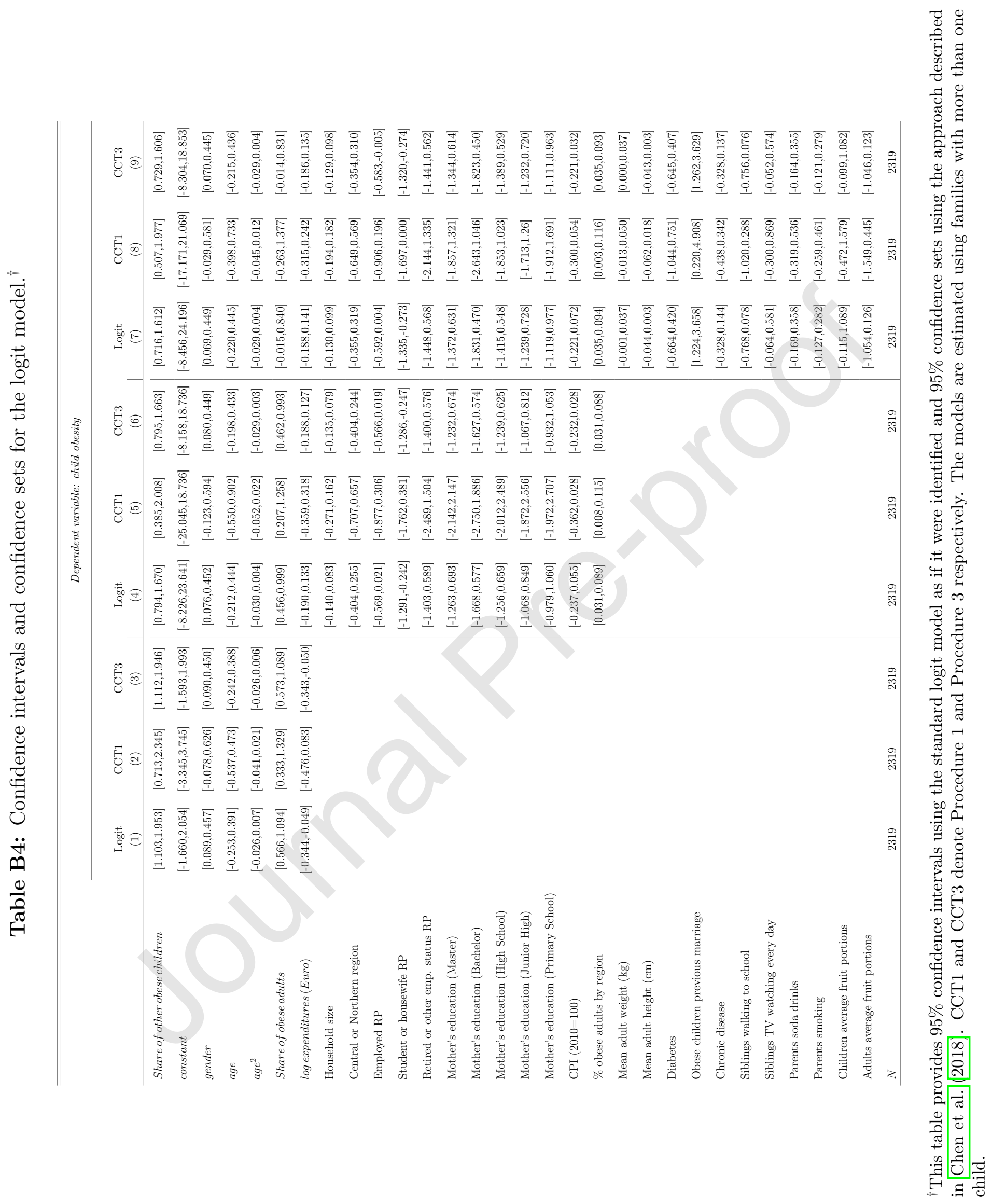




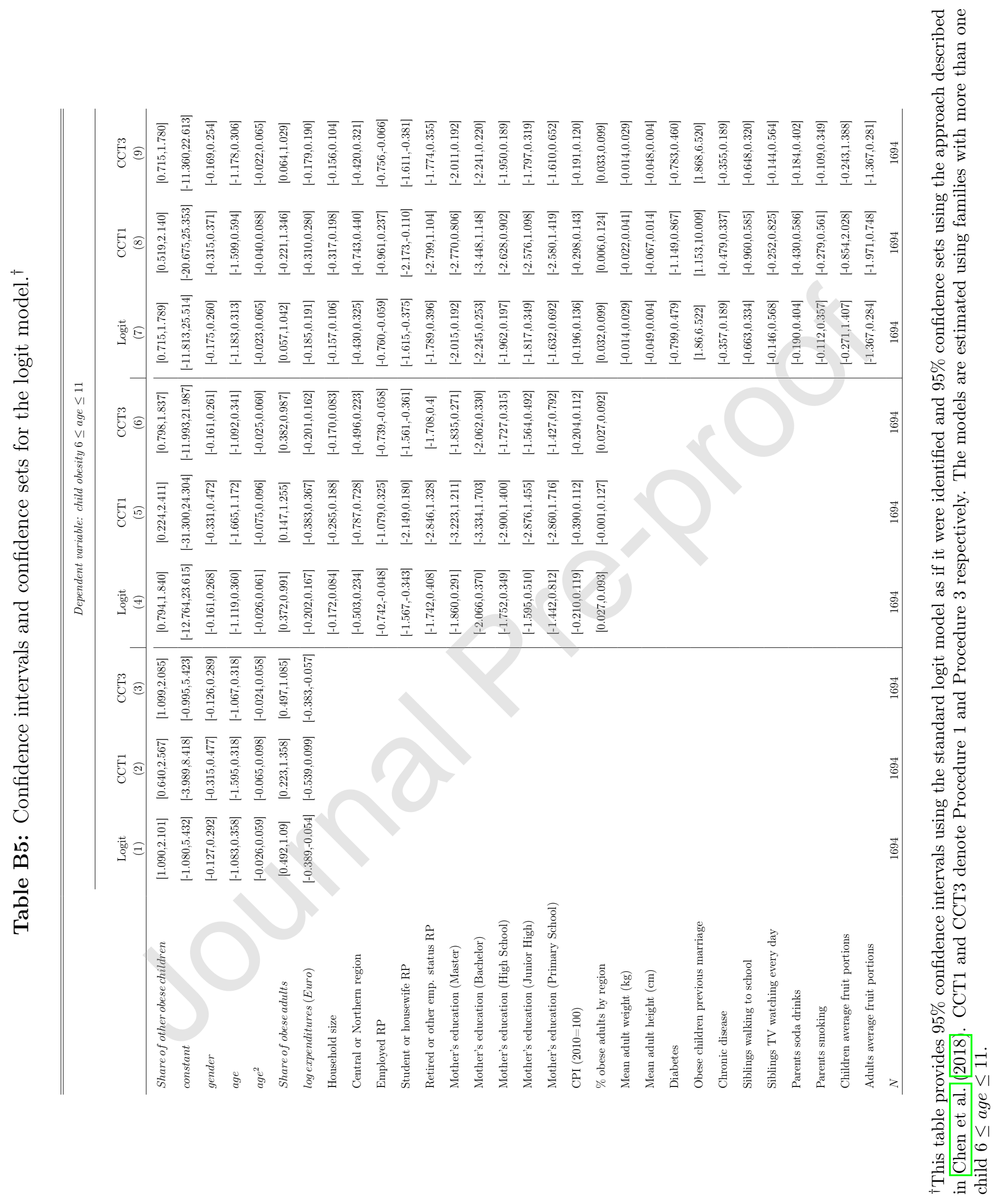




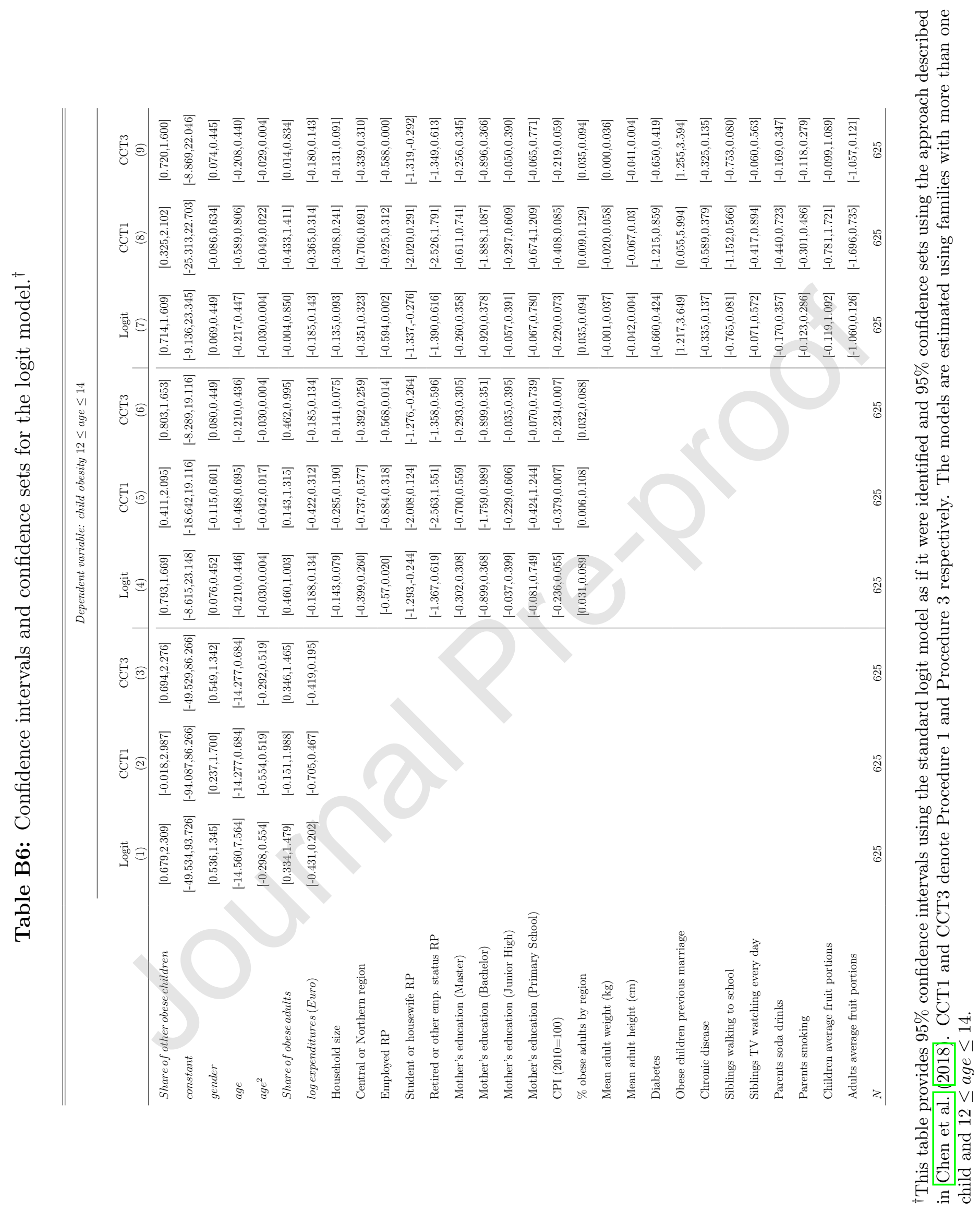


Table B7: Confidence intervals for the logit model. ${ }^{\dagger}$

\begin{tabular}{|c|c|c|c|}
\hline & \multicolumn{3}{|c|}{ Dependent variable: child obesity } \\
\hline & $\begin{array}{l}\text { Logit } \\
(1)\end{array}$ & $\begin{array}{l}\text { Logit } \\
(2)\end{array}$ & $\begin{array}{l}\text { Logit } \\
(3)\end{array}$ \\
\hline constant & {$[-3.946,0.878]$} & {$[-9.973,34.586]$} & {$[-7.155,39.029]$} \\
\hline gender & {$[0.111,0.588]$} & {$[0.124,0.609]$} & {$[0.105,0.597]$} \\
\hline age & {$[-0.149,0.682]$} & {$[-0.137,0.71]$} & {$[-0.183,0.677]$} \\
\hline$a g e^{2}$ & {$[-0.039,0.002]$} & {$[-0.041,0.001]$} & {$[-0.040,0.003]$} \\
\hline Share of obese adults & {$[0.520,1.197]$} & {$[0.443,1.138]$} & {$[-0.457,0.711]$} \\
\hline log expenditures (Euro) & {$[-0.264,0.112]$} & {$[-0.161,0.251]$} & {$[-0.144,0.277]$} \\
\hline Household size & & {$[-0.180,0.105]$} & {$[-0.227,0.069]$} \\
\hline Central or Northern region & & {$[-0.456,0.332]$} & {$[-0.449,0.356]$} \\
\hline Employed RP & & {$[-0.651,0.139]$} & {$[-0.678,0.121]$} \\
\hline Student or housewife RP & & {$[-0.897,0.416]$} & {$[-0.948,0.389]$} \\
\hline Retired or other emp. status RP & & {$[-0.199,1.180]$} & {$[-0.286,1.137]$} \\
\hline Mother's education (Master) & & {$[-0.709,0.825]$} & {$[-0.648,0.920]$} \\
\hline Mother's education (Bachelor) & & {$[-1.879,0.398]$} & {$[-1.985,0.347]$} \\
\hline Mother's education (High School) & & {$[-0.938,0.481]$} & {$[-0.916,0.534]$} \\
\hline Mother's education (Junior High) & & {$[-0.797,0.613]$} & {$[-0.843,0.602]$} \\
\hline Mother's education (Primary) & & {$[-0.629,1.001]$} & {$[-0.627,1.050]$} \\
\hline CPI $(2010=100)$ & & {$[-0.351,0.062]$} & {$[-0.357,0.063]$} \\
\hline$\%$ obese adults by region & & {$[0.006,0.079]$} & {$[0.002,0.076]$} \\
\hline Mean adults weight $(\mathrm{kg})$ & & & {$[0.007,0.060]$} \\
\hline Mean adults height $(\mathrm{cm})$ & & & {$[-0.064,-0.002]$} \\
\hline Diabetes & & & {$[-0.140,1.24]$} \\
\hline Obese children previous marriage & & & {$[1.182,4.561]$} \\
\hline Chronic disease & & & {$[-0.190,0.380]$} \\
\hline Siblings watching TV every day & & & {$[-0.110,0.746]$} \\
\hline Parents soda drinks & & & {$[-0.279,0.388]$} \\
\hline Parents smoking & & & {$[-0.070,0.441]$} \\
\hline Children average fruit portions & & & {$[-1.140,-0.067]$} \\
\hline Adults average fruit portions & & & {$[0.133,1.157]$} \\
\hline$N$ & 1418 & 1418 & 1418 \\
\hline
\end{tabular}

${ }^{\dagger}$ This table provides $95 \%$ confidence intervals using the standard logit model as if it were identified. The models are estimated using families with one child. 
Table B8: Confidence intervals for the logit model. ${ }^{\dagger}$

\begin{tabular}{|c|c|c|c|}
\hline & \multicolumn{3}{|c|}{ Dependent variable: child obesity $(6 \leq$ age $\leq 11)$} \\
\hline & $\begin{array}{c}\text { Logit } \\
\text { (1) }\end{array}$ & $\begin{array}{c}\text { Logit } \\
(2)\end{array}$ & $\begin{array}{c}\text { Logit } \\
(3)\end{array}$ \\
\hline constant & {$[-5.800,3.224]$} & {$[-8.079,50.447]$} & {$[-10.416,50.707]$} \\
\hline gender & {$[-0.274,0.322]$} & {$[-0.287,0.324]$} & {$[-0.325,0.298]$} \\
\hline age & {$[-0.838,1.180]$} & {$[-0.816,1.271]$} & {$[-0.753,1.378]$} \\
\hline$a g e^{2}$ & {$[-0.072,0.045]$} & {$[-0.078,0.044]$} & {$[-0.086,0.038]$} \\
\hline Share of obese adults & {$[0.330,1.185]$} & {$[0.322,1.205]$} & {$[-0.416,1.092]$} \\
\hline log expenditures (Euro) & {$[-0.260,0.212]$} & {$[-0.186,0.343]$} & {$[-0.183,0.359]$} \\
\hline Household size & & {$[-0.198,0.172]$} & {$[-0.266,0.125]$} \\
\hline Central or Northern region & & {$[-0.600,0.372]$} & {$[-0.598,0.401]$} \\
\hline Employed RP & & {$[-0.648,0.428]$} & {$[-0.685,0.399]$} \\
\hline Student or housewife RP & & {$[-0.989,0.66]$} & {$[-1.083,0.603]$} \\
\hline Retired or other emp. status RP & & {$[-0.542,1.377]$} & {$[-0.737,1.295]$} \\
\hline Mother's education (Master) & & {$[-0.861,1.208]$} & {$[-0.775,1.368]$} \\
\hline Mother's education (Bachelor) & & {$[-3.762,-0.098]$} & {$[-3.694,0.051]$} \\
\hline Mother's education (High School) & & {$[-1.286,0.689]$} & {$[-1.206,0.851]$} \\
\hline Mother's education (Junionr High) & & {$[-1.264,0.714]$} & {$[-1.273,0.800]$} \\
\hline Mother's education (Primary) & & {$[-1.167,1.178]$} & {$[-1.09,1.373]$} \\
\hline CPI $(2010=100)$ & & {$[-0.497,0.039]$} & {$[-0.477,0.069]$} \\
\hline$\%$ obese adults by region & & {$[0.005,0.096]$} & {$[0.003,0.097]$} \\
\hline Mean adults weight $(\mathrm{kg})$ & & & {$[-0.016,0.053]$} \\
\hline Mean adults height $(\mathrm{cm})$ & & & {$[-0.059,0.022]$} \\
\hline Diabetes & & & {$[0.124,2.052]$} \\
\hline Obese children previous marriage & & & {$[0.882,5.666]$} \\
\hline Chronic disease & & & {$[-0.484,0.269]$} \\
\hline Siblings watching tv every day & & & {$[-0.298,0.705]$} \\
\hline Parents soda drinks & & & {$[-0.408,0.410]$} \\
\hline Parents smoking & & & {$[-0.203,0.445]$} \\
\hline Children average fruit portions & & & {$[-2.023,-0.356]$} \\
\hline Adults average fruit portions & & & {$[0.353,1.972]$} \\
\hline$N$ & 1694 & 1694 & 1694 \\
\hline
\end{tabular}

${ }^{\dagger}$ This table provides $95 \%$ confidence intervals using the standard logit model as if it were identified. The models are estimated using families with one child and $6 \leq$ age $\leq 11$. 
Table B9: Confidence intervals for the logit model. ${ }^{\dagger}$

\begin{tabular}{|c|c|c|c|}
\hline & \multicolumn{3}{|c|}{ Dependent variable: child obesity $(12 \leq$ age $\leq 14)$} \\
\hline & $\begin{array}{c}\text { Logit } \\
(1) \\
\end{array}$ & $\begin{array}{c}\text { Logit } \\
(2)\end{array}$ & $\begin{array}{c}\text { Logit } \\
(3)\end{array}$ \\
\hline constant & {$[-44.303,96.891]$} & {$[-56.468,104.276]$} & {$[-49.543,117.459]$} \\
\hline gender & {$[0.540,1.376]$} & {$[0.547,1.406]$} & {$[0.524,1.406]$} \\
\hline age & {$[-14.882,6.902]$} & {$[-14.413,7.953]$} & {$[-14.962,8.133]$} \\
\hline$a g e^{2}$ & {$[-0.274,0.564]$} & {$[-0.314,0.547]$} & {$[-0.322,0.567]$} \\
\hline Share of obese adults & {$[0.515,1.656]$} & {$[0.381,1.558]$} & {$[-1.084,0.899]$} \\
\hline log expenditures (Euro) & {$[-0.498,0.134]$} & {$[-0.410,0.274]$} & {$[-0.413,0.304]$} \\
\hline Household size & & {$[-0.302,0.161]$} & {$[-0.351,0.132]$} \\
\hline Central or Northern region & & {$[-0.624,0.764]$} & {$[-0.582,0.840]$} \\
\hline Employed RP & & {$[-0.994,0.207]$} & {$[-1.048,0.198]$} \\
\hline Student or housewife RP & & {$[-1.331,1.011]$} & {$[-1.323,1.068]$} \\
\hline Retired or other emp. status RP & & {$[-0.313,1.661]$} & {$[-0.516,1.534]$} \\
\hline Mother's education (Master) & & {$[-1.554,0.531]$} & {$[-1.456,0.670]$} \\
\hline Mother's education (High School) & & {$[-0.908,1.606]$} & {$[-1.215,1.528]$} \\
\hline Mother's education (Junior high) & & {$[-0.183,0.746]$} & {$[-0.227,0.735]$} \\
\hline Mother's education (Primary) & & {$[-0.175,1.348]$} & {$[-0.237,1.361]$} \\
\hline CPI $(2010=100)$ & & {$[-0.378,0.297]$} & {$[-0.423,0.267]$} \\
\hline$\%$ obese adults by region & & {$[-0.028,0.095]$} & {$[-0.032,0.095]$} \\
\hline Mean adults weight $(\mathrm{kg})$ & & & {$[0.011,0.098]$} \\
\hline Mean adults height $(\mathrm{cm})$ & & & {$[-0.106,-0.002]$} \\
\hline Diabetes & & & {$[-1.157,1.076]$} \\
\hline Obese children previous marrias & & 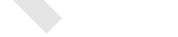 & {$[0.013,5.400]$} \\
\hline Chronic disease & & & {$[-0.061,0.860]$} \\
\hline Siblings watching TV every day & & & {$[-0.234,1.519]$} \\
\hline Parents soda drinks & & & {$[-0.292,0.945]$} \\
\hline Parents smoking & & & {$[-0.190,0.686]$} \\
\hline Children average fruit portions & & & {$[-0.811,0.829]$} \\
\hline Adults average fruit portions & & & {$[-0.610,0.940]$} \\
\hline 8 & 625 & 625 & 625 \\
\hline
\end{tabular}

${ }^{\dagger}$ This table provides $95 \%$ confidence intervals using the standard logit model as if it were identified. The models are estimated using families with one child and $12 \leq$ age $\leq 14$. 


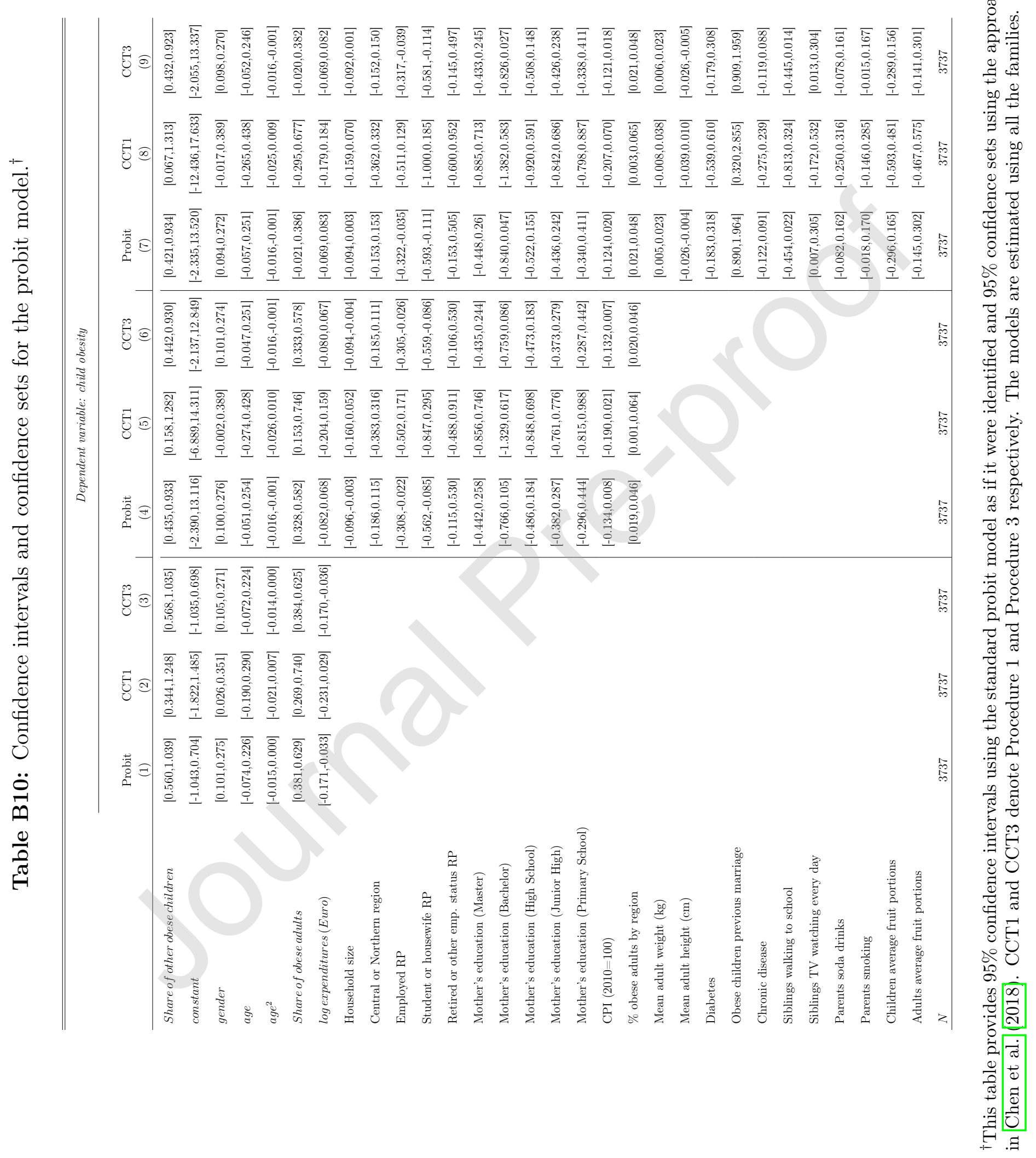




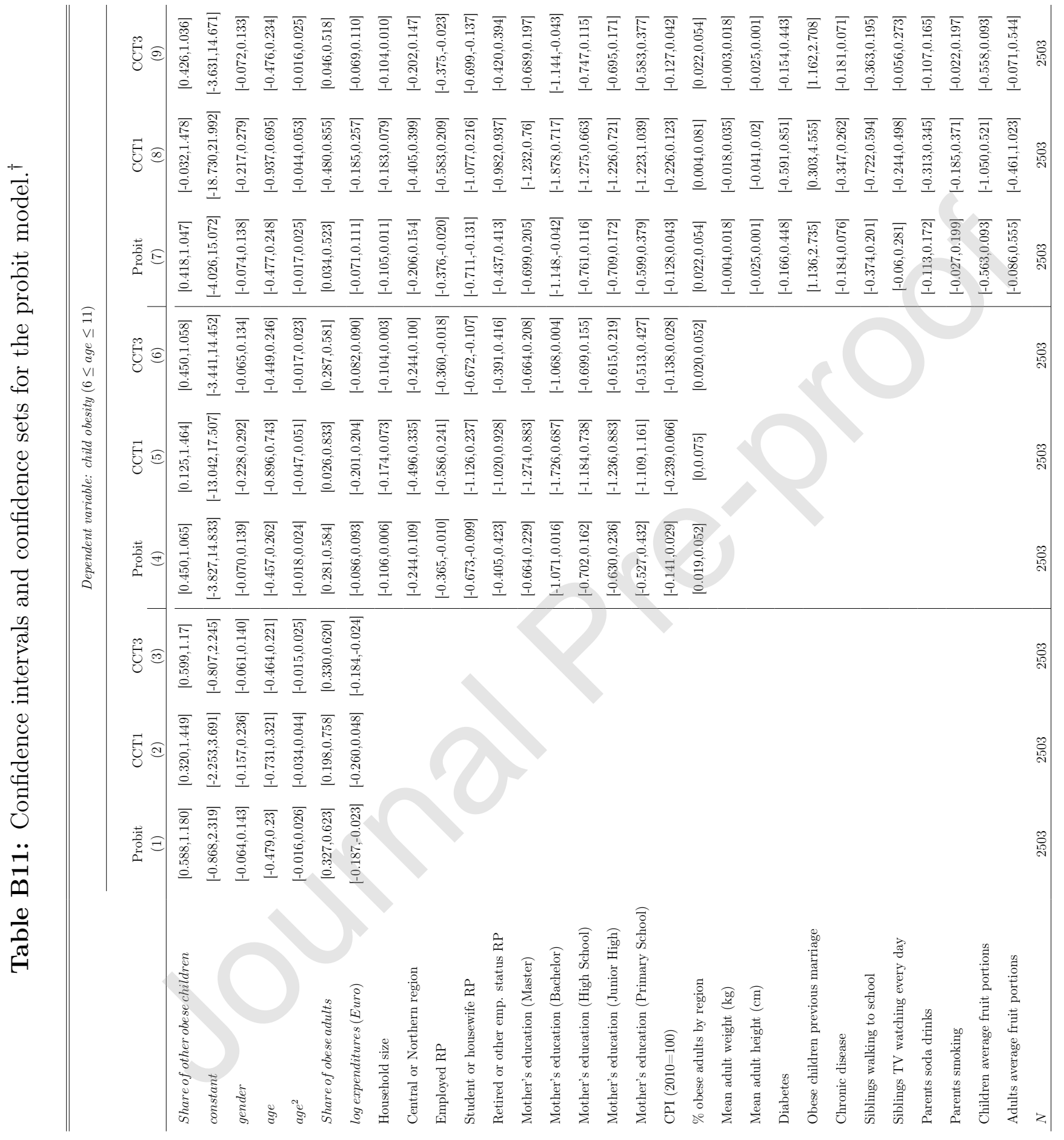

ă. 完 so 


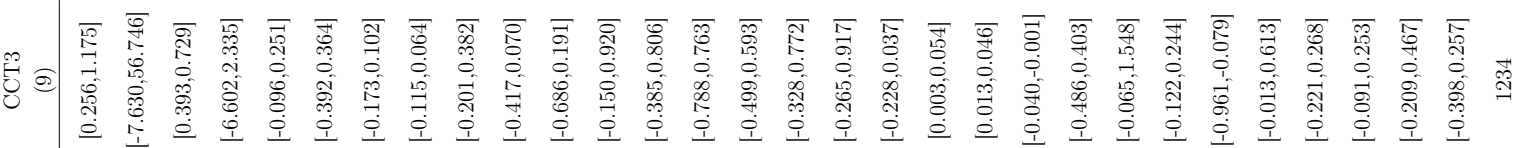

둥

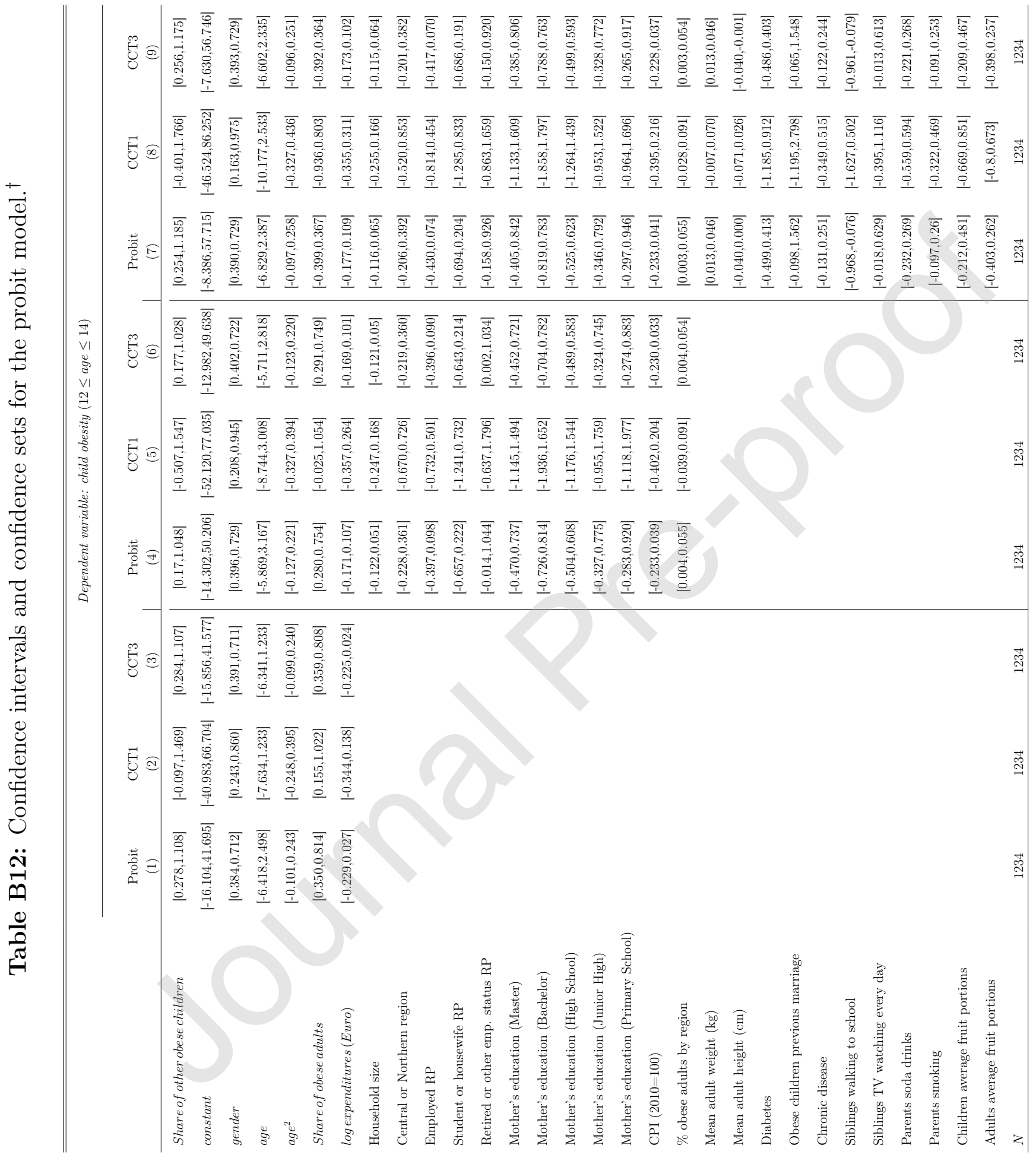

:

.

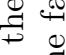

年

콜 그

象.

:

흔

8

용

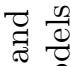

छ

过 


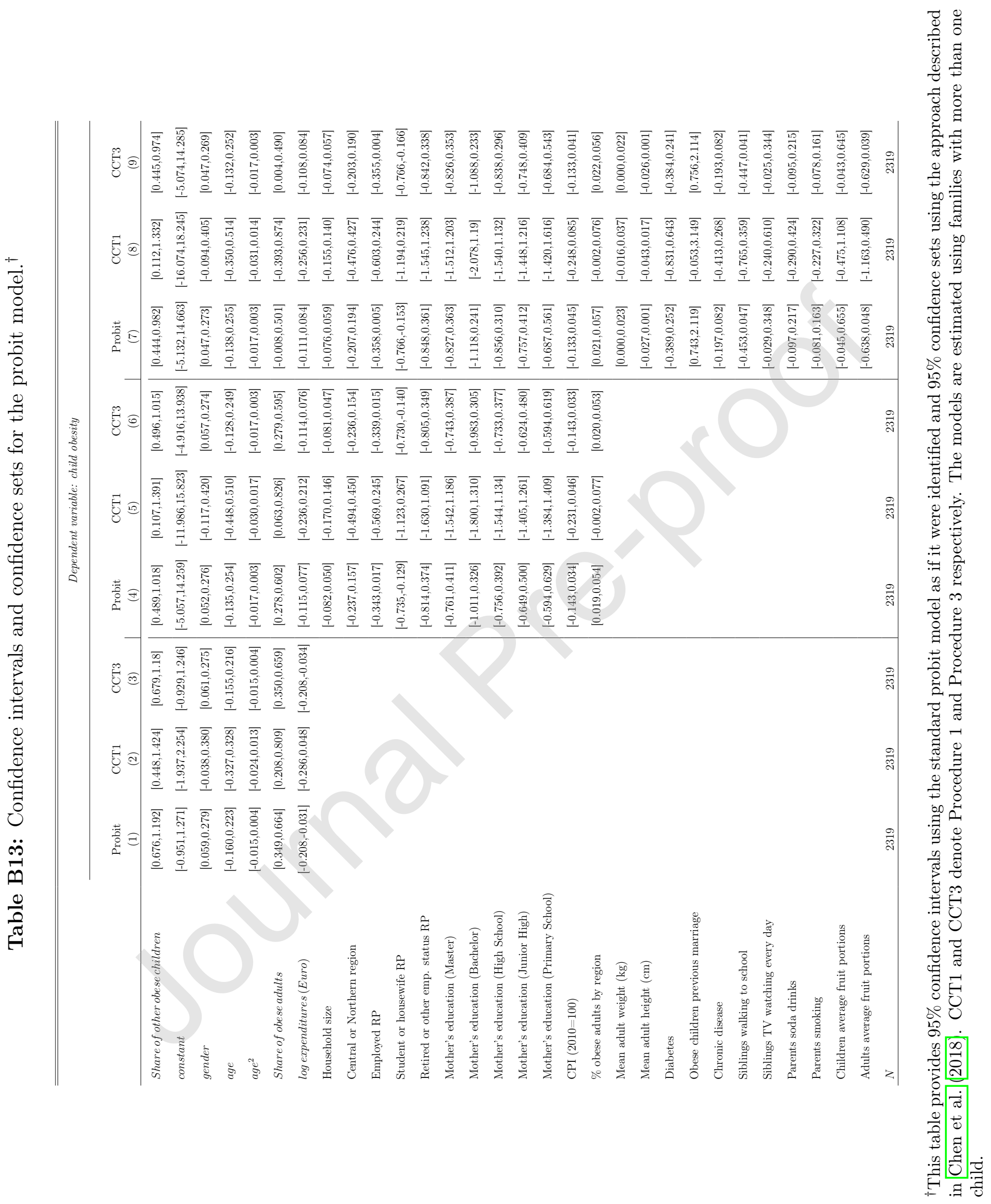




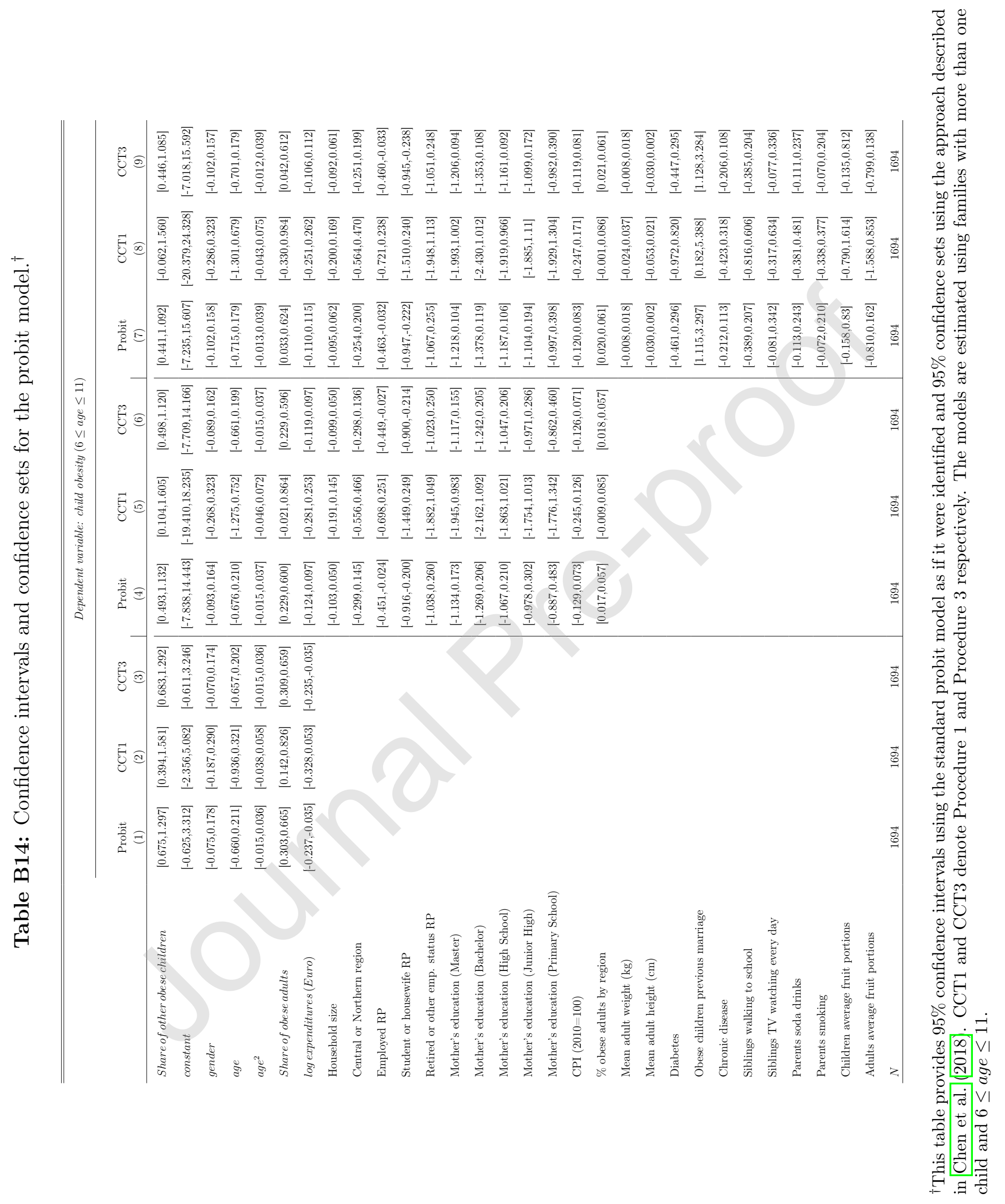




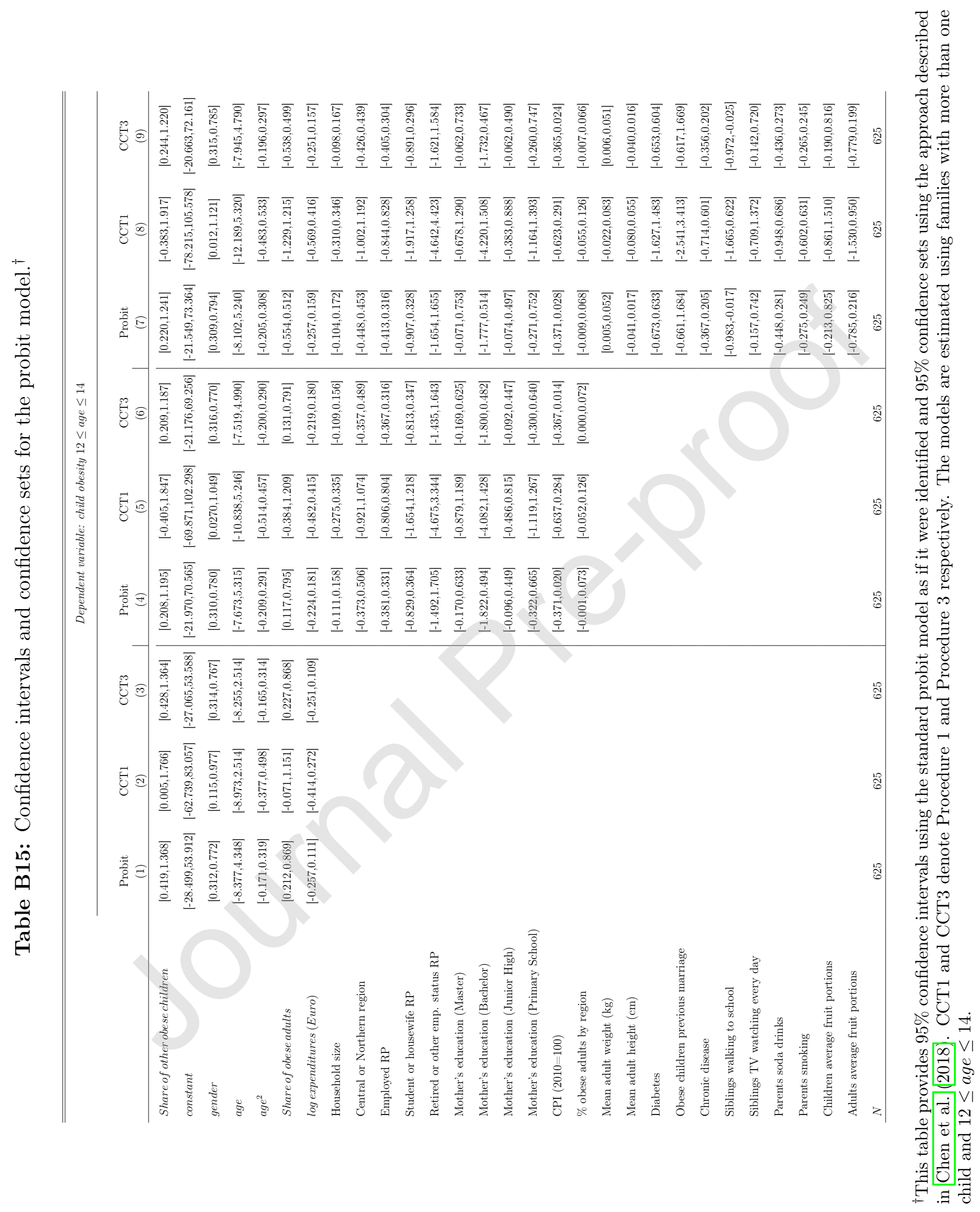


Table B16: Confidence intervals for the probit model. ${ }^{\dagger}$

\begin{tabular}{|c|c|c|c|}
\hline & \multicolumn{3}{|c|}{ Dependent variable: child obesity } \\
\hline & $\begin{array}{l}\text { Probit } \\
\text { (1) }\end{array}$ & $\begin{array}{l}\text { Probit } \\
(2)\end{array}$ & $\begin{array}{l}\text { Probit } \\
\text { (3) }\end{array}$ \\
\hline constant & {$[-2.397,0.491]$} & {$[-6.614,19.885]$} & {$[-5.026,22.394]$} \\
\hline gender & {$[0.076,0.360]$} & {$[0.081,0.369]$} & {$[0.067,0.358]$} \\
\hline age & {$[-0.085,0.412]$} & {$[-0.072,0.433]$} & {$[-0.095,0.417]$} \\
\hline$a g e^{2}$ & {$[-0.024,0.001]$} & {$[-0.025,0.000]$} & {$[-0.024,0.001]$} \\
\hline Share of obese adults & {$[0.313,0.718]$} & {$[0.272,0.685]$} & {$[-0.278,0.417]$} \\
\hline log expenditures (Euro) & {$[-0.157,0.066]$} & {$[-0.098,0.146]$} & {$[-0.085,0.163]$} \\
\hline Household size & & {$[-0.108,0.060]$} & {$[-0.136,0.038]$} \\
\hline Central or Northern region & & {$[-0.269,0.203]$} & {$[-0.262,0.219]$} \\
\hline Employed RP & & {$[-0.394,0.080]$} & {$[-0.410,0.067]$} \\
\hline Student or housewife RP & & {$[-0.535,0.251]$} & {$[-0.567,0.230]$} \\
\hline Retired or other emp. status RP & & {$[-0.115,0.723]$} & {$[-0.167,0.695]$} \\
\hline Mother's education (Master) & & {$[-0.436,0.482]$} & {$[-0.398,0.534]$} \\
\hline Mother's education (Bachelor) & & {$[-1.045,0.243]$} & {$[-1.111,0.212]$} \\
\hline Mother's education (High School) & & {$[-0.571,0.275]$} & {$[-0.552,0.308]$} \\
\hline Mother's education (Junior High) & & {$[-0.491,0.351]$} & {$[-0.515,0.343]$} \\
\hline Mother's education (Primary School) & & {$[-0.389,0.590]$} & {$[-0.384,0.620]$} \\
\hline CPI $(2010=100)$ & & {$[-0.203,0.043]$} & {$[-0.205,0.044]$} \\
\hline$\%$ obese adults by region & & {$[0.004,0.048]$} & {$[0.002,0.046]$} \\
\hline Mean adult weight $(\mathrm{kg})$ & & & {$[0.005,0.036]$} \\
\hline Mean adult height $(\mathrm{cm})$ & & & {$[-0.039,-0.002]$} \\
\hline Diabetes & & & {$[-0.086,0.750]$} \\
\hline Obese children previous marriage & & & {$[0.721,2.535]$} \\
\hline Chronic disease & & & {$[-0.113,0.225]$} \\
\hline Siblings TV watching every day & & & {$[-0.069,0.427]$} \\
\hline Parents soda drinks & & & {$[-0.166,0.230]$} \\
\hline Parents smoking & & & {$[-0.036,0.267]$} \\
\hline Children average fruit portions & & & {$[-0.663,-0.028]$} \\
\hline Adults average fruit portions & & & {$[0.066,0.674]$} \\
\hline$N$ & 1418 & 1418 & 1418 \\
\hline
\end{tabular}

${ }^{\dagger}$ This table provides $95 \%$ confidence intervals using the standard probit model as if it were identified. The models are estimated using families with one child. 
Table B17: Confidence intervals for the probit model. ${ }^{\dagger}$

\begin{tabular}{|c|c|c|c|}
\hline & \multicolumn{3}{|c|}{ Dependent variable: child obesity $(6 \leq$ age $\leq 11)$} \\
\hline & $\begin{array}{c}\text { Probit } \\
\text { (1) }\end{array}$ & $\begin{array}{c}\text { Probit } \\
(2)\end{array}$ & $\begin{array}{c}\text { Probit } \\
(3)\end{array}$ \\
\hline constant & {$[-3.572,1.956]$} & {$[-4.800,30.691]$} & {$[-6.167,30.890]$} \\
\hline gender & {$[-0.164,0.198]$} & {$[-0.175,0.195]$} & {$[-0.194,0.181]$} \\
\hline age & {$[-0.511,0.722]$} & {$[-0.495,0.773]$} & {$[-0.471,0.818]$} \\
\hline$a g e^{2}$ & {$[-0.044,0.028]$} & {$[-0.047,0.026]$} & {$[-0.051,0.024]$} \\
\hline Share of obese adults & {$[0.199,0.718]$} & {$[0.201,0.736]$} & {$[-0.254,0.662]$} \\
\hline log expenditures (Euro) & {$[-0.157,0.130]$} & {$[-0.113,0.205]$} & {$[-0.111,0.214]$} \\
\hline Household size & & {$[-0.121,0.101]$} & {$[-0.157,0.074]$} \\
\hline Central or Northern region & & {$[-0.366,0.222]$} & {$[-0.358,0.245]$} \\
\hline Employed RP & & {$[-0.397,0.256]$} & {$[-0.420,0.236]$} \\
\hline Student or housewife RP & & {$[-0.582,0.408]$} & {$[-0.632,0.374]$} \\
\hline Retired or other emp. status RP & & {$[-0.331,0.849]$} & {$[-0.463,0.785]$} \\
\hline Mother's education (Master) & & {$[-0.527,0.736]$} & {$[-0.486,0.805]$} \\
\hline Mother's education (Bachelor) & & {$[-2.090,-0.080]$} & {$[-2.102,-0.015]$} \\
\hline Mother's education (High School) & & {$[-0.783,0.418]$} & {$[-0.739,0.496]$} \\
\hline Mother's education (Junior High) & & {$[-0.776,0.429]$} & {$[-0.787,0.458]$} \\
\hline Mother's education (Primary School) & & {$[-0.711,0.720]$} & {$[-0.670,0.815]$} \\
\hline CPI $(2010=100)$ & & {$[-0.302,0.023]$} & {$[-0.290,0.041]$} \\
\hline$\%$ obese adults by region & & {$[0.003,0.058]$} & {$[0.002,0.059]$} \\
\hline Mean adult weight $(\mathrm{kg})$ & & & {$[-0.010,0.032]$} \\
\hline Mean adult height $(\mathrm{cm})$ & & & {$[-0.035,0.013]$} \\
\hline Diabetes & & 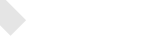 & {$[0.071,1.227]$} \\
\hline Obese children previous marriage & & & {$[0.549,3.038]$} \\
\hline Chronic disease & & & {$[-0.288,0.163]$} \\
\hline Siblings TV watching every day & & & {$[-0.180,0.414]$} \\
\hline Parents soda drinks & & & {$[-0.247,0.245]$} \\
\hline Parents smoking & & & {$[-0.118,0.273]$} \\
\hline Children average fruit portions & & & {$[-1.178,-0.202]$} \\
\hline Adults average fruit portions & & & {$[0.201,1.154]$} \\
\hline$N$ & 1694 & 1694 & 1694 \\
\hline
\end{tabular}

${ }^{\dagger}$ This table provides $95 \%$ confidence intervals using the standard probit model as if it were identified. The models are estimated using families with one child and $6 \leq$ age $\leq 11$. 
Table B18: Confidence intervals for the probit model. ${ }^{\dagger}$

\begin{tabular}{|c|c|c|c|}
\hline & \multicolumn{3}{|c|}{ Dependent variable: child obesity $(12 \leq$ age $\leq 14)$} \\
\hline & $\begin{array}{c}\text { Probit } \\
(1)\end{array}$ & $\begin{array}{c}\text { Probit } \\
(2)\end{array}$ & $\begin{array}{c}\text { Probit } \\
(3)\end{array}$ \\
\hline constant & {$[-26.257,55.215]$} & {$[-35.447,56.664]$} & {$[-30.197,65.458]$} \\
\hline gender & {$[0.316,0.788]$} & {$[0.313,0.795]$} & {$[0.298,0.790]$} \\
\hline age & {$[-8.467,4.092]$} & {$[-7.973,4.870]$} & {$[-8.467,4.783]$} \\
\hline$a g e^{2}$ & {$[-0.163,0.321]$} & {$[-0.193,0.302]$} & {$[-0.189,0.321]$} \\
\hline Share of obese adults & {$[0.304,0.964]$} & {$[0.221,0.897]$} & {$[-0.610,0.528]$} \\
\hline log expenditures (Euro) & {$[-0.287,0.075]$} & {$[-0.239,0.154]$} & {$[-0.237,0.173]$} \\
\hline Household size & & {$[-0.174,0.094]$} & {$[-0.203,0.077]$} \\
\hline Central or Northern region & & {$[-0.352,0.459]$} & {$[-0.324,0.509]$} \\
\hline Employed RP & & {$[-0.588,0.122]$} & {$[-0.618,0.105]$} \\
\hline Student or housewife RP & & {$[-0.761,0.604]$} & {$[-0.765,0.631]$} \\
\hline Retired or other emp. status RP & & {$[-0.181,1.006]$} & {$[-0.302,0.917]$} \\
\hline Mother's education (Master) & & {$[-0.727,0.340]$} & {$[-0.693,0.412]$} \\
\hline Mother's education (Bachelor) & & {$[-0.479,0.962]$} & {$[-0.610,0.931]$} \\
\hline Mother's education (Junior High) & & {$[-0.106,0.427]$} & {$[-0.129,0.421]$} \\
\hline Mother's education (Primary School) & & {$[-0.123,0.789]$} & {$[-0.160,0.790]$} \\
\hline CPI $(2010=100)$ & & {$[-0.205,0.184]$} & {$[-0.232,0.163]$} \\
\hline$\%$ obese adults by region & & {$[-0.015,0.057]$} & {$[-0.017,0.057]$} \\
\hline Mean adult weight $(\mathrm{kg})$ & & & {$[0.006,0.056]$} \\
\hline Mean adult height $(\mathrm{cm})$ & & & {$[-0.060,-0.001]$} \\
\hline Diabetes & & & {$[-0.682,0.628]$} \\
\hline Obese children previous marriage & & 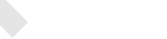 & {$[0.020,2.806]$} \\
\hline Chronic disease & & & {$[-0.045,0.490]$} \\
\hline Siblings TV watching every day & & & {$[-0.114,0.849]$} \\
\hline Parents soda drinks & & & {$[-0.173,0.541]$} \\
\hline Parents smoking & & & {$[-0.094,0.412]$} \\
\hline Children average fruit portions & & & {$[-0.472,0.489]$} \\
\hline Adults average fruit portions & & & {$[-0.367,0.541]$} \\
\hline$N$ & 625 & 625 & 625 \\
\hline
\end{tabular}

${ }^{\dagger}$ This table provides $95 \%$ confidence intervals using the standard probit model as if it were identified. The models are estimated using families with one child and $12 \leq$ age $\leq 14$. 
Table B19: Confidence intervals and confidence sets for the logit model with group dummies. ${ }^{\dagger}$

\begin{tabular}{|c|c|c|c|c|c|c|}
\hline & \multicolumn{6}{|c|}{ Dependent variable: child obesity } \\
\hline & $\begin{array}{l}\text { Logit } \\
\text { (1) }\end{array}$ & $\begin{array}{c}\text { CCT1 } \\
(2) \\
\end{array}$ & $\begin{array}{c}\text { CCT3 } \\
(3) \\
\end{array}$ & $\begin{array}{c}\text { Logit } \\
(4)\end{array}$ & $\begin{array}{c}\text { CCT1 } \\
(5)\end{array}$ & $\begin{array}{c}\text { CCT3 } \\
(6) \\
\end{array}$ \\
\hline Share of other obese children & {$[0.467,0.952]$} & {$[0.163,1.261]$} & {$[0.474,0.951]$} & {$[0.487,0.973]$} & {$[0.224,1.267]$} & {$[0.488,0.972]$} \\
\hline gender & {$[0.107,0.282]$} & {$[0.004,0.403]$} & {$[0.109,0.278]$} & {$[0.106,0.281]$} & {$[0.009,0.389]$} & {$[0.109,0.281]$} \\
\hline age & {$[-0.076,0.226]$} & {$[-0.299,0.410]$} & {$[-0.070,0.224]$} & {$[-0.076,0.227]$} & {$[-0.261,0.432]$} & {$[-0.072,0.222]$} \\
\hline$a g e^{2}$ & {$[-0.015,0.000]$} & {$[-0.024,0.012]$} & {$[-0.015,0.000]$} & {$[-0.015,0.000]$} & {$[-0.026,0.010]$} & {$[-0.015,0.000]$} \\
\hline Share of obese adults & {$[0.020,0.421]$} & {$[-0.236,0.705]$} & {$[0.021,0.420]$} & {$[0.012,0.414]$} & {$[-0.234,0.715]$} & {$[0.015,0.408]$} \\
\hline log expenditures (Euro) & {$[-0.126,0.020]$} & {$[-0.22,0.126]$} & {$[-0.126,0.017]$} & {$[-0.137,0.008]$} & {$[-0.225,0.096]$} & {$[-0.134,0.005]$} \\
\hline average adult weight & {$[0.007,0.024]$} & {$[-0.004,0.037]$} & {$[0.007,0.024]$} & {$[0.007,0.024]$} & {$[-0.008,0.037]$} & {$[0.007,0.024]$} \\
\hline average adult height & {$[-0.029,-0.008]$} & {$[-0.042,0.007]$} & {$[-0.029,-0.008]$} & {$[-0.029,-0.008]$} & {$[-0.042,0.006]$} & {$[-0.029,-0.008]$} \\
\hline group 1 & {$[-0.157,3.202]$} & {$[-2.009,5.206]$} & {$[-0.114,3.165]$} & {$[0.222,3.602]$} & {$[-2.15,5.641]$} & {$[0.29,3.595]$} \\
\hline group 2 & {$[-0.065,3.290]$} & {$[-1.850,5.345]$} & {$[-0.033,3.238]$} & {$[0.109,3.504]$} & {$[-2.532,5.584]$} & {$[0.173,3.452]$} \\
\hline group 3 & {$[-0.178,3.217]$} & {$[-2.196,5.315]$} & {$[-0.148,3.191]$} & {$[0.327,3.680]$} & {$[-2.160,5.866]$} & {$[0.353,3.677]$} \\
\hline group 4 & {$[-0.036,3.347]$} & {$[-1.855,5.369]$} & {$[-0.030,3.326]$} & {$[-0.246,3.190]$} & {$[-2.753,5.395]$} & {$[-0.202,3.173]$} \\
\hline group 5 & {$[0.032,3.377]$} & {$[-1.821,5.333]$} & {$[0.058,3.310]$} & {$[0.127,3.541]$} & {$[-2.519,5.660]$} & {$[0.207,3.512]$} \\
\hline group 6 & {$[0.234,3.559]$} & {$[-1.675,5.573]$} & {$[0.302,3.523]$} & {$[-0.078,3.312]$} & {$[-2.519,5.380]$} & {$[-0.076,3.263]$} \\
\hline group 7 & {$[-0.138,3.209]$} & {$[-2.046,5.163]$} & {$[-0.080,3.197]$} & {$[-0.042,3.348]$} & {$[-2.729,5.438]$} & {$[-0.007,3.293]$} \\
\hline group 8 & {$[0.162,3.494]$} & {$[-1.841,5.672]$} & {$[0.208,3.471]$} & {$[-0.171,3.261]$} & {$[-2.948,5.413]$} & {$[-0.161,3.218]$} \\
\hline group 9 & {$[0.026,3.38]$} & {$[-1.837,5.419]$} & {$[0.069,3.367]$} & {$[-0.136,3.271]$} & {$[-2.558,5.500]$} & {$[-0.116,3.221]$} \\
\hline group 10 & {$[-0.024,3.337]$} & {$[-1.837,5.436]$} & {$[0.000,3.305]$} & {$[0.190,3.585]$} & {$[-2.411,5.679]$} & {$[0.204,3.554]$} \\
\hline group 11 & & & & {$[0.023,3.406]$} & {$[-2.490,5.477]$} & {$[0.085,3.385]$} \\
\hline group 12 & & & & {$[0.078,3.490]$} & {$[-2.617,5.790]$} & {$[0.101,3.412]$} \\
\hline group 13 & & & & {$[-0.213,3.288]$} & {$[-2.986,5.667]$} & {$[-0.189,3.220]$} \\
\hline group 14 & & & & {$[-0.002,3.384]$} & {$[-2.175,5.595]$} & {$[0.022,3.319]$} \\
\hline group 15 & & & & {$[-0.030,3.343]$} & {$[-2.633,5.385]$} & {$[-0.015,3.340]$} \\
\hline group 16 & & & & {$[0.092,3.460]$} & {$[-1.787,5.625]$} & {$[0.107,3.402]$} \\
\hline group 17 & & & & {$[-0.275,3.200]$} & {$[-3.005,5.305]$} & {$[-0.235,3.123]$} \\
\hline group 18 & & & & {$[0.015,3.422]$} & {$[-2.528,5.575]$} & {$[0.035,3.342]$} \\
\hline group 19 & & & & {$[-0.040,3.350]$} & {$[-2.582,5.468]$} & {$[0.020,3.272]$} \\
\hline group 20 & & & & {$[0.395,3.842]$} & {$[-2.071,6.180]$} & {$[0.429,3.763]$} \\
\hline$N$ & 3737 & 3737 & 3737 & 3737 & 3737 & 3737 \\
\hline
\end{tabular}

${ }^{\dagger}$ This table provides $95 \%$ confidence intervals using the standard logit model as if it were identified and $95 \%$ confidence sets using the approach described in Chen et al. (2018). CCT1 and CCT3 denote Procedure 1 and Procedure 3 respectively. Each family is assigned to a group via a $k$-prototypes algorithm, for each group we include a dummy variable. 
Table B20: Confidence intervals and confidence sets for the probit model with group dummies. $^{\dagger}$

\begin{tabular}{|c|c|c|c|c|c|c|}
\hline & \multicolumn{6}{|c|}{ Dependent variable: child obesity } \\
\hline & $\begin{array}{l}\text { Probit } \\
\text { (1) }\end{array}$ & $\begin{array}{c}\text { CCT1 } \\
(2) \\
\end{array}$ & $\begin{array}{c}\text { CCT3 } \\
(3) \\
\end{array}$ & $\begin{array}{c}\text { Probit } \\
\text { (4) }\end{array}$ & $\begin{array}{c}\text { CCT1 } \\
(5) \\
\end{array}$ & $\begin{array}{c}\text { CCT3 } \\
(6) \\
\end{array}$ \\
\hline Share of other obese children & {$[0.756,1.552]$} & {$[0.237,1.953]$} & {$[0.757,1.537]$} & {$[0.793,1.592]$} & {$[0.485,1.844]$} & {$[0.801,1.583]$} \\
\hline gender & {$[0.169,0.462]$} & {$[0.054,0.621]$} & {$[0.174,0.460]$} & {$[0.167,0.461]$} & {$[0.082,0.583]$} & {$[0.168,0.456]$} \\
\hline age & {$[-0.131,0.376]$} & {$[-0.364,0.605]$} & {$[-0.129,0.370]$} & {$[-0.124,0.385]$} & {$[-0.288,0.571]$} & {$[-0.115,0.379]$} \\
\hline$a g e^{2}$ & {$[-0.025,0.001]$} & {$[-0.036,0.012]$} & {$[-0.025,0.001]$} & {$[-0.025,0.000]$} & {$[-0.038,0.009]$} & {$[-0.025,0.000]$} \\
\hline Share of obese adults & {$[0.041,0.711]$} & {$[-0.278,1.019]$} & {$[0.050,0.705]$} & {$[0.023,0.695]$} & {$[-0.193,0.910]$} & {$[0.030,0.687]$} \\
\hline log expenditures (Euro) & {$[-0.210,0.033]$} & {$[-0.331,0.148]$} & {$[-0.210,0.032]$} & {$[-0.229,0.013]$} & {$[-0.287,0.084]$} & {$[-0.227,0.009]$} \\
\hline average adult weight & {$[0.010,0.040]$} & {$[-0.003,0.052]$} & {$[0.011,0.039]$} & {$[0.010,0.040]$} & {$[0.004,0.054]$} & {$[0.011,0.040]$} \\
\hline average adult height & {$[-0.048,-0.012]$} & {$[-0.065,0.000]$} & {$[-0.048,-0.013]$} & {$[-0.048,-0.012]$} & {$[-0.057,-0.002]$} & {$[-0.048,-0.012]$} \\
\hline group 1 & {$[-0.316,5.327]$} & {$[-3.352,7.938]$} & {$[-0.273,5.315]$} & {$[0.274,5.950]$} & {$[-1.893,7.583]$} & {$[0.309,5.860]$} \\
\hline group 2 & {$[-0.156,5.482]$} & {$[-3.178,8.151]$} & {$[-0.088,5.405]$} & {$[0.114,5.817]$} & {$[-2.436,7.313]$} & {$[0.125,5.738]$} \\
\hline group 3 & {$[-0.343,5.361]$} & {$[-3.168,7.947]$} & {$[-0.249,5.253]$} & {$[0.480,6.114]$} & {$[-2.144,7.964]$} & {$[0.511,6.024]$} \\
\hline group 4 & {$[-0.110,5.576]$} & {$[-3.265,7.969]$} & {$[-0.088,5.473]$} & {$[-0.468,5.308]$} & {$[-2.889,7.083]$} & {$[-0.370,5.270]$} \\
\hline group 5 & {$[0.001,5.621]$} & {$[-3.021,8.157]$} & {$[0.027,5.560]$} & {$[0.150,5.884]$} & {$[-2.379,7.396]$} & {$[0.188,5.816]$} \\
\hline group 6 & {$[0.336,5.923]$} & {$[-2.550,8.450]$} & {$[0.339,5.895]$} & {$[-0.196,5.498]$} & {$[-2.712,7.028]$} & {$[-0.154,5.454]$} \\
\hline group 7 & {$[-0.276,5.347]$} & {$[-3.067,7.818]$} & {$[-0.208,5.289]$} & {$[-0.127,5.571]$} & {$[-2.767,7.214]$} & {$[-0.045,5.500]$} \\
\hline group 8 & {$[0.207,5.804]$} & {$[-2.807,8.426]$} & {$[0.257,5.703]$} & {$[-0.346,5.419]$} & {$[-3.036,7.181]$} & {$[-0.250,5.323]$} \\
\hline group 9 & {$[-0.006,5.629]$} & {$[-2.784,8.013]$} & {$[0.052,5.614]$} & {$[-0.292,5.430]$} & {$[-2.775,6.868]$} & {$[-0.242,5.407]$} \\
\hline group 10 & {$[-0.095,5.553]$} & {$[-3.141,8.177]$} & {$[-0.054,5.548]$} & {$[0.249,5.954]$} & {$[-2.240,7.834]$} & {$[0.304,5.900]$} \\
\hline group 11 & & & & {$[-0.021,5.665]$} & {$[-2.925,7.195]$} & {$[0.039,5.662]$} \\
\hline group 12 & & & & {$[0.073,5.811]$} & {$[-2.443,7.652]$} & {$[0.107,5.715]$} \\
\hline group 13 & & & & {$[-0.426,5.467]$} & {$[-2.566,7.094]$} & {$[-0.419,5.435]$} \\
\hline group 14 & & & & {$[-0.067,5.623]$} & {$[-2.686,7.286]$} & {$[0.034,5.573]$} \\
\hline group 15 & & & & {$[-0.106,5.56]$} & {$[-2.494,7.140]$} & {$[-0.061,5.486]$} \\
\hline group 16 & & & & {$[0.084,5.742]$} & {$[-2.441,7.309]$} & {$[0.120,5.734]$} \\
\hline group 17 & & & & {$[-0.522,5.330]$} & {$[-2.963,7.085]$} & {$[-0.426,5.258]$} \\
\hline group 18 & & & & {$[-0.038,5.687]$} & {$[-2.500,7.262]$} & {$[-0.035,5.684]$} \\
\hline group 19 & & & & {$[-0.129,5.567]$} & {$[-2.953,7.140]$} & {$[-0.098,5.508]$} \\
\hline group 20 & & & & {$[0.587,6.366]$} & {$[-1.911,8.061]$} & {$[0.607,6.349]$} \\
\hline$N$ & 3737 & 3737 & 3737 & 3737 & 3737 & 3737 \\
\hline
\end{tabular}

${ }^{\dagger}$ This table provides $95 \%$ confidence intervals using the standard probit model as if it were identified and 95\% confidence sets using the approach described in Chen et al. (2018). CCT1 and CCT3 denote Procedure 1 and Procedure 3 respectively. Each family is assigned to a group via a $k$-prototypes algorithm, for each group we include a dummy variable.

\section{References}

2 Chen, X., Christensen, T. \& Tamer, E. (2018). Monte Carlo confidence sets for identified $3 \quad$ sets. Econometrica.

4 Cohen, M. L. (1991). Statistical matching and microsimulation models. In C. F. Citro \&

${ }_{5}$ E. A. Hanushek (Eds.), Improving information for social policy decisions - the uses of 
$1 \quad$ microsimulation modeling: Volume II, technical papers (pp. 62-88). National Academy 2 Press.

3 D'Orazio, M., Zio, M. D. \& Scanu, M. (2006). Statistical Matching: Theory and Practice $4 \quad$ (Wiley Series in Survey Methodology). John Wiley \& Sons.

5 Radner, D., Allen, R., Gonzalez, M., Jabine, T. \& Muller, H. (1980). Report on exact and $6 \quad$ statistical matching techniques. Statistical Policy Working Paper 5. U.S. Department of $7 \quad$ of Commerce, Office of Federal Statistical Policy and Standards.

8 Raghunathan, T. E., Lepkowski, J. M., Van Hoewyk, J. \& Solenberger, P. (2001). A mul$9 \quad$ tivariate technique for multiply imputing missing values using a sequence of regression $10 \quad$ models. Survey Methodology, 27(1), 85-96.

11 Rodgers, W. L. (1984). An evaluation of statistical matching. Journal of Business \& 12 Economic Statistics, 2(1), 91-102.

13 Szepannek, G. (2018). clustMixType: User-Friendly Clustering of Mixed-Type Data in R.

14 The $R$ Journal, 10(2), 200-208. Retrieved from https://doi.org/10.32614/RJ-2018

$15 \quad-048$ doi: 10.32614/RJ-2018-048 